
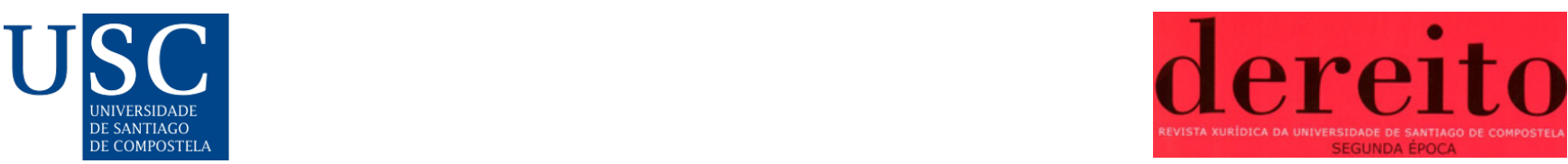

Dereito: revista xurídica da Universidade de Santiago de Compostela, 30(2), 2021. ISSN-e: 2174-0690

https://doi.org/10.15304/dereito.30.2.7656

Estudios

\title{
LOS HEREDEROS ESPECIALMENTE PROTEGIDOS EN EL DERECHO CUBANO
}

The specially protected heirs in Cuban law

\section{Vincenzo Barba}

Catedrático de derecho civil, Universidad de Roma "La Sapienza", Italia

vincenzo.barba@uniroma1.it

\section{Resumen}

El artículo analiza la regulación de la sucesión necesaria en el derecho cubano, identificando las condiciones y los remedios, y señalando que la legítima cubana, en contra de una opinión generalizada, es una legítima protectora y no tiene contenido asistencial. En el derecho cubano, la mera existencia de una relación de parentesco con el fallecido (matrimonio, descendencia, ascendencia) no es suficiente para la atribución de la condición de legitimario, ya que deben cumplirse dos importantes requisitos: la inaptitud a trabajar y la dependencia económica. Desde este punto de vista, me parece que el derecho cubano podría ser tomado como modelo en otras legislaciones, precisamente para encontrar un importante y nuevo equilibrio entre la libertad de testar y la protección de los legitimarios.

Palabras clave: Herederos especialmente protegidos; legítima; legitimarios; sucesión necesaria; derecho cubano; derecho de complemento; acción de reducción.

\begin{abstract}
The article analyses the regulation of the necessary succession in Cuban law, identifying the conditions and remedies, and pointing out that the Cuban legitimate succession, contrary to a generalised opinion, is a protective legitimate succession and does not have a welfare content. In Cuban law, the mere existence of a kinship relationship with the deceased (marriage, descent, ancestry) is not sufficient for the attribution of the status of legitimaire, since two important requirements must be met: inability to work and economic dependence. From this point of view, it seems to me that Cuban law could be taken as a model for other legislations, precisely in order to find an important new balance between the freedom to testate and the protection of the legitimated persons.
\end{abstract}

Keywords: Specially protected heirs; legitimate heirs; necessary succession; Cuban law; right of complement; action for reduction. 


\section{SUMARIO}

1. INTRODUCCIÓN.

2. LA LEGÍTIMA CUBANA DESDE EL PUNTO DE VISTA DE SU FUNCIÓN Y DE SU CONTENIDO.

3. MÉTODOS DE CÁLCULO DE LA LEGÍTIMA.

4. HEREDEROS ESPECIALMENTE PROTEGIDOS.

4.1. Hijos, cónyuge y ascendientes.

4.2. El requisito de no aptitud para trabajar.

4.3. El requisito de la dependencia económica del causante.

5. LA PROTECCIÓN DE LOS HEREDEROS ESPECIALMENTE PROTEGIDOS.

5.1. La protección cualitativa de la legítima.

5.2. Protección cuantitativa de la legítima.

6. CONCLUSIÓN.

5.3. La preterición del heredero especialmente protegido.

7. Bibliografía.

\section{INTRODUCCIÓN}

La regulación de protección de los herederos especialmente protegidos en el derecho cubano se recoge en el libro cuarto del Código Civil, dedicado al derecho de sucesiones, en los artículos de 492 a $495^{1}$.

El artículo 492 establece que la cuota reservada es igual a la mitad del caudal hereditario, con la consecuencia de que la libertad del testador, en presencia de herederos especialmente protegidos, se limita a la mitad de su patrimonio, precisando que, en todo caso, el testador no puede imponer gravamen y cargas sobre la legítima.

El artículo 493 establece que son herederos especialmente protegidos los hijos, el cónyuge y los ascendientes, siempre que no estén aptos para trabajar y dependan económicamente del testador, precisando que, en caso de concurrencia de varios herederos, la legítima se divide entre ellos por partes iguales.

El art. 494 establece que el heredero especialmente protegido que haya recibido una parte de la herencia inferior a la que le corresponde podrá pedir el complemento de la legítima.

Por último, el art. 495 establece que la preterición de alguno o de todos los herederos especialmente protegidos existentes en el momento de otorgar el testamento o nacidos después de la muerte del testador anula la institución de heredero, mientras que los legados que no excedan de la parte de los bienes de que el testador puede disponer libremente quedan intactos.

A estas disposiciones, dedicadas específicamente a los herederos especialmente protegidos, hay que añadir la norma del artículo 378, letra a), que establece la inoficiosidad de la donación que exceda de la porción disponible, y el artículo 76, letra d), según el cual son rescindibles los actos válidamente realizados por el donante en caso de donación inoficiosa.

Las normas de protección de los herederos especialmente protegidos, resumidas en estos cuatro importantes artículos del Código Civil, plantean muchos problemas, tanto teóricos como prácticos. En primer lugar, es necesario establecer si la legítima en el derecho cubano debe o no 
ser considerada puramente asistencial, y, en todo caso, es imprescindible identificar y aclarar las condiciones bajo las cuales es posible hablar de herederos especialmente protegidos, así como los medios y remedios de protección.

En el derecho cubano la mera existencia de una relación familiar con el causante (matrimonio, descendencia, ascendencia) no es suficiente para la atribución de la cualidad de heredero especialmente protegido $^{2}$. Además se necesitan dos requisitos importantes: que la persona no esté apta para trabajar y que sea económicamente dependiente del causante ${ }^{3}$. No es casualidad que en el derecho cubano se prefiera a la expresión "legitimarios" la de "herederos especialmente protegidos", con la que, en mi opinión, se pretende resaltar que el ordenamiento jurídico no se limita a proteger a los sujetos sólo por su vínculo familiar, sino cuando existen circunstancias que justifican la especial protección que el ordenamiento jurídico les reserva ${ }^{4}$.

No puede decirse, sin embargo, que en el derecho cubano la legítima tenga un contenido puramente asistencial, pues consiste en una cuota de la herencia que asciende a la mitad del caudal hereditario, con independencia del número y concurrencia de los herederos especialmente protegidos. A este respecto, el más importante jurista de la nación, LEONARDO PÉREZ GALLARDO ${ }^{5}$, ofrece doce razones para confirmar esta tesis.

Desde este punto de vista, me parece que el derecho cubano merece la máxima consideración y que debería ser tomado como modelo en otras legislaciones, precisamente por encontrar un importante y nuevo equilibrio entre la libertad de testar y los derechos correspondientes a los herederos especialmente protegidos. Se trata de un modelo que merecería ser importando en Europa, donde la legítima se configura, en general, como una prestación económica debida por la sola relación familiar con el causante y con total independencia de la verdadera necesitad del legitimario y de su verdadera y concreta relación con el causante, de modo que ya tuve ocasión de decir que los legitimarios son titulares de una "renta por su posición familiar"6.

\section{LA LEGÍTIMA CUBANA DESDE EL PUNTO DE VISTA DE SU FUNCIÓN Y DE SU CONTENIDO}

Haciendo una ejemplificación vistosa, en sí misma inadecuada para comprender la complejidad del fenómeno, podría decirse que la regulación de la llamada sucesión necesaria puede responder, desde un punto de vista puramente funcional, a dos lógicas profundamente diferentes, aunque en muchos aspectos capaces de cruzarse; por un lado, la legítima como atribución hereditaria legal forzosa y, por otro, la legítima como regulación negativa ${ }^{7}$.

En algunos ordenamientos jurídicos, sucesión necesaria ha tenido y sigue teniendo la función prioritaria de asegurar a los legitimarios la adquisición de la condición de heredero, mientras que, en otros ordenamientos jurídicos, en los que situaría al derecho cubano, la función que prevalece es la de asegurar a los legitimarios una parte del caudal hereditario ${ }^{8}$.

Las dos perspectivas son muy diferentes ${ }^{9}$.

En un caso, la ley quiere que los legitimarios se conviertan en herederos y la legítima constituye una pars hereditatis. La ley establece mecanismos para que se conviertan en herederos ipso iure, es decir, independientemente de la voluntad del testador y de una iniciativa judicial ${ }^{10}$. Esto puede lograrse técnicamente ya sea asignando al testamento la única función de ordenar 
legados, impidiendo que el testador pueda instituir herederos, o, con alguna mayor dificultad de coordinación, limitando la capacidad del testador de instituir herederos a la sola cuota de libre disposición. En un caso, los herederos están siempre determinados por la ley, de modo que los herederos siempre serán llamados a la sucesión ipso iure. En el segundo caso, si el testador hubiera establecido herederos por encima de la cuota de libre disposición, el testamento sería nulo o parcialmente nulo, con la consecuencia de que los legitimarios, en cualquier caso, serían llamados a heredar ipso iure e independientemente de la iniciativa judicial de ellos.

En esta perspectiva, precisamente porque la función principal de la regulación es garantizar a los legitimarios la cualidad de herederos, la ley se preocupa de indicar las cuotas en las que los legitimarios deben convertirse en herederos, de modo que la legítima constituye efectivamente una pars hereditatis. De ello se desprende que la llamada sucesión necesaria debe considerarse un tipo específico de sucesión, autónomo tanto respecto a la sucesión intestada como a la testamentaria ${ }^{11}$.

En la otra perspectiva, en la que se puede situar el derecho cubano, y también el español y el italiano, el interés protegido es garantizar que los legitimarios consigan una parte del patrimonio hereditario u otros derechos, independientemente de que adquieran también la condición de heredero. Por el contrario, parece que la condición de heredero no solo no es esencial ni decisiva, sino que podría faltar por completo. El legislador no se preocupa de que los legitimarios se conviertan en herederos, sino de que consigan una parte de los bienes hereditarios o unos derechos especiales, siendo irrelevante el título de esa adquisición.

En esta perspectiva, debe excluirse firmemente que la sucesión necesaria constituya una sucesión autónoma respecto a la sucesión intestada (o legítima) y a la testamentaria, ya que se trata de una mera regulación de protección de los legitimarios, destinada a aplicarse cualquiera que sea la fuente de la sucesión y que tiene una función de freno o de regulación negativa.

El instrumento técnico mediante el cual la ley garantiza a los legitimarios conseguir una parte del caudal hereditario depende de la forma en que cada ordenamiento considere la legítima o, más precisamente, el contenido de la legítima. A este respecto, también a título de ejemplo, pueden aislarse al menos cuatro sistemas diferentes, según que la legítima se entienda como pars valoris, como pars valoris bonorum, como pars valoris bonorum qua in specie heres solvere debet, como pars bonorum $^{12}$.

La diferencia entre estos cuatro sistemas radica en el contenido del derecho que corresponde al legitimario, mientras que no depende de los presupuestos ${ }^{13}$.

En el primer caso, se atribuye al legitimario un mero derecho de crédito, que también puede pagarse con dinero no hereditario; en el segundo caso, el legitimario tiene derecho a una parte del valor de la herencia, garantizada por los bienes que componen el patrimonio hereditario; en el tercer caso, el legitimario tiene derecho a un valor fijo, que debe satisfacerse con los bienes hereditarios; en el último caso, el legitimario tiene derecho a la copropiedad de los bienes hereditarios.

A la luz de estas breves consideraciones, me parece que la legítima en el derecho cubano debe ser apreciada en su aspecto funcional como regulación negativa. El interés predominante de la ley cubana es que los herederos especialmente protegidos, siempre y cuando se den las condiciones, reciban una determinada cantidad de bienes de la herencia. No es imprescindible que reciban estos bienes en concepto de herencia, ya que también pueden haberlos recibido en otro concepto, como se desprende del art. 494 del Código Civil, según el cual el heredero especialmente protegido sólo tiene derecho a reclamar el complemento si ha recibido "por cualquier título" menos de la porción que le 
corresponde. Esto significa que si el heredero especialmente protegido hubiera recibido a título de donación bienes por un valor correspondiente a la cuota que le corresponde, no tendría ninguna acción, ni tendría derecho a reclamar su condición de heredero. La adquisición de la condición de heredero es, por lo tanto, funcional a conseguir una determinada porción del haber hereditario, mientras que no es indispensable en sí misma. No se protege el derecho a ser heredero por sí, sino el derecho a conseguir una porción del caudal hereditario.

Además, desde un punto de vista sustantivo, parece que la legítima debe considerarse pars bonorum, ya que confiere al beneficiario no solo el derecho a una parte de la herencia, sino también la posibilidad de satisfacer este crédito mediante bienes que forman parte de la herencia ${ }^{14}$.

Si el heredero especialmente protegido ha sido instituido heredero, pero no ha conseguido bienes suficientes para la porción que le corresponde, tiene derecho a pedir el complemento y, por tanto, a pedir la reducción de las disposiciones testamentarias (véase el art. 495.2 del Código Civil) y de las posibles donaciones (véase el art. 378, let. a) del Código Civil). En caso contrario, si no se le instituyera heredero, podría solicitar, en virtud del artículo 495 del Código Civil, la anulación de las instituciones hereditarias, con la consecuencia de que sucedería en la cuota vacante y, por tanto, podría obtener los bienes hereditarios.

En definitiva, en el sistema jurídico cubano, la legítima es, desde el punto de vista funcional, una disciplina negativa o restrictiva, mientras que desde el punto de vista del contenido, una pars bonorum. Por otra parte, no cabe duda de que la condición de heredero especialmente protegido debe considerarse excepcional (pues que es excepcional que una persona dependa económicamente del causante y no tenga aptitud para trabajar) y transitoria (pues que no es una condición permanente de la persona), que ha de constatarse en el momento de la apertura de la sucesión ${ }^{15}$. Al estar íntimamente ligada a la persona y a su condición, es intransmisible y libremente renunciable. Evidentemente, tiene una evidente finalidad de protección y bienestar para las personas.

\section{MÉTODOS DE CÁLCULO DE LA LEGÍTIMA}

El ordenamiento jurídico cubano se limita a señalar que la legítima es igual a la mitad de la herencia, pero no existe ninguna norma sobre cómo se debe calcular este valor ${ }^{16}$. Sin embargo, teniendo en cuenta que el art. 387 a) del Código civil establece la ineficacia de la donación que exceda la cuota de libre disposición, debe concluirse que, de forma similar a lo establecido en el derecho civil español, para establecer la base del cálculo debe tenerse en cuenta no sólo la herencia activa sino también las donaciones.

Por tanto, para calcular la legítima no es necesario y suficiente considerar el patrimonio hereditario activo, sino un patrimonio ficticio. Se requieren tres datos: a) el valor económico de los bienes efectivamente dejados por el causante o, más exactamente, el valor económico de todos los bienes que pertenecían al causante en el momento de su muerte y que son susceptibles de ser transmitidos (el "relictum"); b) el valor económico de las deudas heredadas, es decir, de todas las deudas que el testador tenía antes de su muerte, así como las relacionadas con su muerte, como, por ejemplo, las deudas por gastos funerarios (el "debitum"); c) el valor económico de todas las donaciones y liberalidades que el causante realizó durante su vida a favor de cualquier persona (el "donatum"). 
Con estos tres datos es posible determinar el valor de la herencia ficticia que es relevante a efectos de determinar la legítima. Del relictum hay que restar el debitum y, a la diferencia, hay que añadir el donatum. Se deduce, por tanto, que la fórmula de la reunión ficticia es relictum - debitum + donatum.

Al tratarse de cantidades que expresan datos económico-patrimoniales, siempre tienen un valor positivo, por lo que, si el debitum es mayor que el relictum, el resultado siempre será 0, ya que no es posible dar un resultado negativo.

Si el relictum fuera 100, el debitum 50 y el donatum 70, el valor del patrimonio ficticio, es decir, de los bienes sobre los que se debe calcular la legítima es de 120; si el relictum fuera igual a 50, el debitum a 100 y el donatum a 100, el valor del llamado patrimonio ficticio es de 100. En el caso de herencia pasiva, es decir, en el caso de que el debitum es mayor que el relictum, la masa ficticia es igual al valor del donatum ${ }^{17}$.

Cabe señalar que la reunión ficticia es una mera operación matemática, ya que sólo sirve para identificar el valor del caudal hereditario. Este valor es ficticio, porque se consideran bienes que no pertenecían al causante en el momento de su muerte. Además, la sustracción del debitum al relictum constituye una operación puramente matemática, ya que no importa la liquidación, ni la necesidad de proveer a su pago.

Una vez identificado el valor concreto del caudal hereditario ficticio, se puede determinar a cuánto asciende la legítima ${ }^{18}$, que se repartirá, por partes iguales, entre todos los herederos especialmente protegidos que tengan derecho a ella ${ }^{19}$.

Una vez determinada la porción de legítima a la que tiene derecho realmente cada heredero especialmente protegido, es posible determinar si ha conseguido menos de lo que le correspondía. Para ello es necesario comparar lo que ha concretamente conseguido con lo que tenía derecho a conseguir.

Para determinar la cuantía que el heredero especialmente protegido ha conseguido en concepto de legítima, hay que tener en cuenta no sólo lo que ha conseguido en concepto de herencia, sino también lo que ha recibido del causante en concepto de legado o de donaciones inter vivos, salvo que el donante le haya dispensado expresamente.

La función de la dispensa de imputación, de hecho, es evitar que el heredero especialmente protegido tenga que atribuir a su propia legítima el bien objeto de la donación realizada por un acto entre vivos (donación o liberalidad indirecta) o por un acto de última voluntad distinto de la institución del heredero (legado u otra disposición de bienes), de modo que la atribución debe considerarse como hecha a cargo de la cuota de libre disposición, es decir, como realizada en exceso de lo que le corresponde en concepto de legítima. Obviamente, la dispensa de imputación no puede ser efectiva más allá de la cuota de libre disposición y no puede ir en detrimento de los donatarios anteriores.

En definitiva, las normas de imputación pueden resumirse como sigue.

Las liberalidades inter vivos y los legados efectuados en favor de los herederos especialmente protegidos se consideran realizados como anticipo de legítima o por cuenta de la legítima (es decir, deben imputarse a su legítima) salvo que el testador haya dispuesto lo contrario, en cuyo caso la donación se imputa a la cuota de libre disposición.

Las liberalidades inter vivos hechas a extraños (mejor: a sujetos distintos de los herederos especialmente protegidos) se imputan a la cuota de libre disposición y, si son inoficiosas, se reducen de acuerdo con el art. 378, letra a) del Código Civil. Los legados atribuidos a extraños se imputan 
a la cuota de libre disposición y, en el caso de que sean inoficiosos, se reducen según el art. 495.2 del Código Civil.

La relevancia de las donaciones confirma, además, que la protección de los herederos especialmente protegidos opera no sólo en el caso de sucesión testamentaria, sino también en caso de sucesión intestada, pues bien podría ocurrir que el testador haya dispuesto de bienes en exceso de la cuota de libre disposición mediante donaciones, con la consecuencia de que, incluso en presencia de una sucesión enteramente intestada, los herederos especialmente protegidos podrían conseguir menos de lo que les corresponde ${ }^{20}$.

Si el testador en vida hubiese donado a extraños primero un bien que vale 100 y luego otro que vale 60 y a su muerte deja un bien que vale 40 y como únicos herederos a su cónyuge y a un hijo. Suponiendo que tanto la esposa como el hijo sean herederos especialmente protegidos, no cabe duda de que, aunque sean herederos únicos, se produciría un perjuicio. Como herederos especialmente protegidos tienen derecho a la $1 / 2$ del caudal hereditario, es decir, un valor de 100 ( $1 / 2$ de: relictum 40 - debitum 0 + donatum 160). A titulo de herederos recibirán 40 (todo el relictum), por lo que tendrán que pedir el complemento de la legítima, a través la interposición de una acción de reducción de la última donación, para que, en caso de que se deje sin efecto, puedan adquirir 60 .

\section{HEREDEROS ESPECIALMENTE PROTEGIDOS}

Los herederos especialmente protegidos están indicados en el art. 493 del Código Civil, que establece que esta condición jurídica la tienen los hijos, el cónyuge y los ascendientes, siempre que no estén aptos para trabajar y dependan económicamente del causante ${ }^{21}$.

De esta disposición legal se desprenden al menos tres características fundamentales de la legítima cubana y las dos últimas la diferencian del derecho español y italiano.

En primer lugar, se trata de una legítima fija, que asciende a la mitad de la herencia, con independencia del número y la categoría de los herederos especialmente protegidos. Además, la presencia de hijos no excluye a los ascendientes del grupo de herederos especialmente protegidos, como ocurre en los sistemas jurídicos español e italiano.

En segundo lugar, la legítima se reparte por igual entre todos los herederos especialmente protegidos (en Italia es muy diferente ${ }^{22}$ ), con independencia del número y categoría de herederos especialmente protegidos que puedan concurrir en una determinada sucesión; esto es, no hay mejora ni otra institución similar.

Por último, y este es el aspecto de mayor interés, la condición de heredero especialmente protegido requiere no sólo la existencia de una relación de parentesco o matrimonio con el causante, sino la concurrencia de dos importantes requisitos: la inaptitud para trabajar y la dependencia económica $^{23}$. «En cuanto a la primera implica cierta imposibilidad física o síquica del sujeto para realizar por sí mismo una labor productiva que le permita obtener remuneración y dentro de esta acepción se incluyen los menores de edad, los ancianos con impedimentos físicos y o mentales sin pensión por jubilación, y por su parte la dependencia económica representa la sujeción monetaria de una persona respecto a otra, en este caso en relación con el causante de la sucesión» ${ }^{24}$.

Estos dos requisitos deben existir en el momento de la apertura de la sucesión, mientras que es irrelevante que existan en el momento en que el testador ha otorgado su testamento. 
Se debate si los requisitos deben permanecer hasta el momento de la partición de la herencia y si deben existir en el momento en que se interpone una demanda de reducción de las disposiciones testamentarias o de las donaciones.

Aunque el principio de que la aceptación surte efecto en el momento de la apertura de la sucesión podría llevar a una solución negativa, el fundamento de la legítima en el derecho cubano debe llevar a una solución antitética. Razonar de otro modo, de hecho, acabaría atribuyendo la legítima a una persona que en ese momento concreto no se encuentra en esa condición excepcional que justifica la limitación de la libertad de testar.

En consecuencia, no sólo es necesario que la persona reúna las condiciones para ser considerada heredero especialmente protegido en el momento de la apertura de la sucesión, sino que debe conservarlas hasta el momento de la partición de la herencia o hasta el momento en que solicite el complemento ${ }^{25}$. Por ello, PÉREZ GALLARDO ${ }^{26}$ dice: «sería necesario, entonces, valorar en casos determinados y no en todos, si sería conveniente variar el tan discutido momento de apreciación de los presupuestos legales».

El ordenamiento jurídico cubano, con esta disciplina, ha pretendido limitar la libertad de testar solo cuando existan razones objetivas que puedan justificar esta limitación ${ }^{27}$. Esto queda claro en las palabras del Tribunal Supremo: «debe entenderse que la novedosa institución del heredero especialmente protegido que tutela nuestro Código Civil, deviene ante todo limitación al soberano derecho de testar libremente, de donde sólo por causas especiales y fehacientemente demostradas puede someterse a cuestionamiento el libre ejercicio de la facultad de una persona de disponer libremente sobre sus bienes para después de su muerte, y así la aplicación del precepto señalado como infringido requiere la concurrencia simultánea e inequívoca de los tres requisitos exigidos» ${ }^{28}$.

A diferencia del sistema jurídico español o italiano, no basta con una relación parental o conyugal. Además -y esto no se puede obviar- la referencia a estos dos requisitos (la no aptitud para trabajar y la dependencia económica del causante) hace de la legítima un tipo de medida excepcional, ya que la mayoría de las personas no se encuentran en esta situación de vulnerabilidad ${ }^{29}$.

La determinación de estos dos requisitos no es en absoluto sencilla y, como demuestra la abundante jurisprudencia al respecto, se plantean numerosos problemas.

\subsection{Hijos, cónyuge y ascendientes}

Los herederos especialmente protegidos son los hijos, el cónyuge y los ascendientes.

a) La primera categoría de sujetos que se menciona entre los herederos especialmente protegidos es la de los hijos, especificando que, en caso de su muerte prematura, se extiende a los descendientes.

No hay diferencia entre los hijos, pues en la legislación cubana, cualquier posible distinción, según hayan nacido dentro o fuera del matrimonio, ya había sido eliminada por la anterior Constitución, cuyo artículo 37, que establecía la igualdad de todos los hijos, había obligado a modificar el Código de Familia. El principio, por supuesto, ha sido reiterado en la reciente Constitución de 2018, en el artículo 84, que no solo establece que todos los hijos tienen los mismos derechos, sino que incluso «se prohíbe toda calificación sobre la naturaleza de la filiación».

La letra de la norma sugiere que los descendientes del hijo pueden ser herederos especialmente protegidos únicamente en caso de muerte prematura de su padre. Esta interpretación literal del 
precepto ha sido criticada, con razón, por PÉREZ GALLARDO ${ }^{30}$, quien considera más correcto afirmar que los descendientes pueden ser también herederos especialmente protegidos con el hijo, siempre y cuando reúnan las dos condiciones exigidas por la ley. En este sentido, el ilustre estudioso cubano señala que bien podría darse el caso de que el causante tenga como dependientes económicamente tanto a su propio hijo como a sus nietos (los hijos de su hijo), por lo que considerar solo al hijo como heredero especialmente protegido y no también al resto de los descendientes (los nietos) sería improcedente. Más aún si se tiene en cuenta que al momento de identificar a los ascendientes, el legislador cubano no hace distinción alguna entre ellos, con el paradójico resultado que, en caso de fallecimiento del causante, tanto los padres del causante como los eventuales abuelos podrían unirse a los hijos y al cónyuge. Por ello, es preferible una interpretación correctora de la norma, que considera herederos especialmente protegidos tanto al hijo como a los descendientes, aunque el hijo no sea premuerto ${ }^{31}$.

Obviamente, cuando los hijos son menores de edad en el momento del fallecimiento de su progenitor, es plausible suponer que deben considerarse herederos especialmente protegidos. La jurisprudencia cubana se ha pronunciado en numerosas ocasiones en este sentido. No obstante, cabe señalar que el hecho de que haya menores no debe considerarse, a mi parecer, un factor, por sí mismo, necesario y suficiente para afirmar que ellos son herederos especialmente protegidos ${ }^{32}$. Si bien es cierto que en la mayoría de los casos los menores no están aptos para trabajar y dependen económicamente de su progenitor, esto no excluye la posibilidad de que existan casos excepcionales en los que no exista dicha dependencia ${ }^{33}$. Piénsese en el caso de un menor que haya recibido una importante herencia de un tío, por lo que hay que excluir que dependa económicamente de su padre. Por otro lado, es absolutamente irrelevante que el progenitor no haya cumplido con su obligación de contribuir a los alimentos del menor durante su vida, también porque excluir, en este caso, la condición de heredero especialmente protegido perjudicaría doblemente al hijo, privándole, después de haber sido privado de los alimentos debidos en vida, también de sus derechos sucesorios ${ }^{34}$.

En definitiva, es cierto que el menor de edad debe ser considerado heredero especialmente protegido, pero hay que evitar el error de afirmarlo a priori, como parece leerse en algunas sentencias del Tribunal Supremo ${ }^{35}$. A efectos de comprobar si se cumplen los requisitos es relevante el momento del fallecimiento del testador; por ello, el hijo menor de 18 años, que no había sido reconocido cuando se hizo el testamento, fue reconocido como heredero especialmente protegido ${ }^{36}$.

Por último, se considera que la asistencia a cursos preuniversitarios, sobre todo cuando éstos impiden la inserción en un centro de trabajo, es idónea para considerar al sujeto como heredero especialmente protegido ${ }^{37}$.

b) Otro heredero especialmente protegido es el cónyuge sobreviviente.

Esta condición se aplica en el caso de un matrimonio formalizado cuyo vínculo no ha sido disuelto por una sentencia firme de divorcio o de nulidad matrimonial o por un documento público de divorcio autorizado por escritura pública. Es imprescindible que haya una sentencia firme y, en su defecto, el cónyuge conserva su condición de heredero especialmente protegido. El sobreviviente de una unión de hecho recibe el mismo trato que el cónyuge y se puede solicitar, de acuerdo con el artículo 18 del Código de Familia, el reconocimiento de esta unión matrimonial no formalizada, siempre que se cumplan los requisitos de singularidad, estabilidad y capacidad jurídica de los miembros de la pareja ${ }^{38}$. 
La separación de hecho no conlleva la pérdida de la condición de heredero especialmente protegido. Sin embargo, en el caso de una separación que lleva mucho tiempo, en el curso de la cual uno o ambos cónyuges han establecido nuevas relaciones familiares, no cabe duda de que el supérstite no tendrá la condición de heredero especialmente protegido, porque debe excluirse que dependa económicamente del otro. En un caso singular, el Tribunal Supremo excluyó la condición de heredero especialmente protegido al cónyuge que había vuelto a vivir en el domicilio familiar, después de haber vivido fuera durante mucho tiempo, a petición del hijo y sin establecer con su esposa una relación sustancialmente análoga a la del matrimonio ${ }^{39}$.

c) Finalmente, la última categoría considerada es la de los ascendientes.

Como ya he dicho, el legislador no diferencia en función de su grado de proximidad al de cuius, con lo que tanto los padres como los abuelos, si se cumplen los requisitos legales, podrían asumir simultáneamente la condición de herederos especialmente protegidos.

\subsection{El requisito de no aptitud para trabajar}

El primero de los dos requisitos necesarios para que el sujeto sea considerado heredero especialmente protegido es su ineptitud para trabajar, es decir, la situación objetiva de no poder realizar una actividad laboral ${ }^{40}$.

La expresión "no aptitud para trabajar" pretende referirse a cualquier situación de imposibilidad física o psíquica que impida a una persona desarrollar una actividad laboral o, más exactamente, formar parte de una relación laboral que permita una remuneración suficiente para llevar una vida independiente.

Las personas menores de edad no tienen aptitud para trabajar. En este sentido, cabe destacar que, según la legislación cubana, la mayoría de edad se adquiere con el cumplimiento de los 18 años, sin embargo, el menor que ha cumplido 17 años tiene la capacidad de ser parte de un contrato de trabajo, mientras que sólo en casos muy excepcionales los menores que tienen 15 y 16 años tienen la capacidad de ser parte de un contrato de trabajo. A la luz de estas consideraciones, se supone generalmente que un menor carece de aptitud para trabajar, salvo que, excepcionalmente, realice una actividad laboral.

No tienen aptitud para trabajar las personas mayores o de la tercera edad ${ }^{41} \mathrm{y}$, por supuesto, las personas con una discapacidad que les impide trabajar en concreto.

Más allá de estas indicaciones, no es posible elaborar una lista precisa de personas que cumplen el requisito de "no aptitud para trabajar", ya que se trata de una cuestión de hecho que debe verificarse en cada caso concreto.

Una cuestión compleja es la de los hijos que asisten a cursos universitarios, pues existen orientaciones contrastadas del Tribunal Supremo.

Según una primera orientación, se debe considerar que un estudiante universitario tiene aptitud para trabajar, sobre todo teniendo en cuenta el Decreto-Ley n. 268/2009 de 26 de junio "Modificativo del régimen laboral" que permite la posibilidad de que los estudiantes universitarios puedan realizar un trabajo, siempre que no comprometa su rendimiento. Claramente, en una decisión muy importante de 2011, leemos: «ya era mayor de edad, y en plena aptitud para trabajar, pero carecía de actitud para hacerlo, pues en su caso optó por continuar vinculado al Sistema Nacional de Educación, al habérsele asignado una carrera universitaria, esa fue su elección» ${ }^{42}$. 
Aunque la anterior debe considerarse la interpretación preferente, más recientemente el Tribunal Supremo ha cambiado su orientación, afirmando que el estudiante que cursa una carrera universitaria debe considerarse siempre en situación sustancial de ineptitud para trabajar, con lo que, si depende económicamente de su padre, debe considerarse un heredero especialmente protegido $^{43}$.

\subsection{El requisito de la dependencia económica del causante}

El segundo de los dos requisitos para que la persona sea considerada heredero especialmente protegido es su dependencia económica del causante, es decir, aquella situación de subordinación económica tal que la persona no pueda satisfacer sus necesidades básicas por sus propios medios ${ }^{44}$.

La expresión "dependencia económica” constituye una verdadera cláusula general que, como tal, requiere una valoración de cada caso concreto y no se presta a una definición circunscrita. $\mathrm{Su}$ apreciación debe ser específica para cada caso, teniendo en cuenta las circunstancias de cada caso, y su flexibilidad permite que la ley pueda adaptarse a los rápidos cambios sociales. Como señala PÉREZ GALLARDO ${ }^{45}$ «las normas jurídicas deben interpretarse a tono con el momento de su aplicación, de manera que lo jueces sean un puente entre el legislador y las personas en su dimensión de sujetos del derecho, más allá del dictado literal conforme con el tiempo en que fue sancionada una norma».

En términos generales, puede decirse que la dependencia económica presupone una situación estable o permanente de subordinación económica, que puede darse no solo cuando una parte recibe dinero del causante para satisfacer sus necesidades, sino también en todos los casos en los que el causante, sin dar dinero, sostiene o se hace cargo de todas o muchas de las necesidades vitales de la persona, de modo que ésta se encuentra en una situación de evidente vulnerabilidad económica. En otras palabras, es importante tener en cuenta que el concepto de dependencia económica, por un lado, no presupone necesariamente que una parte pague a la otra una cantidad de dinero y, por otro, no puede excluirse por el mero hecho de que la persona reciba una pensión. Lo que se requiere es que una persona esté a cargo, de manera estable, de otra persona, que se ocupe principalmente de sus necesidades esenciales ${ }^{46}$.

Cabe añadir que el concepto de dependencia económica no implica necesariamente el de convivencia, ya que dicha situación puede darse también entre personas que no conviven. El único requisito necesario y suficiente es que la persona se encuentre en una situación de vulnerabilidad económica tal que, sin el apoyo del otro, no podría satisfacer todas sus necesidades básicas y no podría seguir llevando una existencia libre y digna.

En la jurisprudencia cubana se ha desarrollado un debate muy importante sobre la posibilidad de considerar a una persona jubilada en condición de dependencia económica.

En un primer momento, el Tribunal Supremo afirmó que la titularidad de una pensión excluye la posibilidad de considerar a su titular en situación de dependencia económica. En 2004 se argumentó la exclusión afirmando que la demandante siempre había tenido ingresos propios consistentes, primero, en su salario como trabajadora y, después, en su pensión ${ }^{47}$; en 2007 porque era beneficiaria de una prestación de la Seguridad Social ${ }^{48}$.

Un punto de inflexión importante se produjo en 2012 cuando el Tribunal Supremo declaró que el disfrute de una pensión no excluye por sí mismo la condición de dependencia económica ${ }^{49}$, que 
debe ser valorada en el caso concreto. Aunque después de esta decisión en algunos casos el Tribunal Supremo volvió a la primera interpretación ${ }^{50}$, no cabe duda de que ahora hay más flexibilidad en la interpretación de esta cláusula general.

A este respecto, cabe mencionar una sentencia reciente que establece: «permite colegir que, aunque percibía una pensión primero ascendente a ciento sesenta pesos y luego incrementada a doscientos pesos, dicha prestación resultaba a todas luces insuficiente para satisfacer los gastos corrientes de persona de la tercera edad, requerida de alimentación balanceada y que debía adquirir medicamentos regulados que conllevaban a la erogación de gran parte de lo que recibía por seguridad social, de manera que para su subsistencia le resultaba indispensable el aporte económico de su cónyuge, quien se desempeñaba como albañil hasta que este falleció [...] con el que conformó una unidad económica de la que dependía [...]» ${ }^{51}$.

En este sentido, es significativo que la jurisprudencia cubana haya afirmado que también puede darse una situación de dependencia económica en el caso de dos cónyuges, ambos con ingresos propios, que conviven, cuando los ingresos de uno solo no son suficientes para satisfacer las necesidades de ambos, por lo que dependen mutuamente uno del otro. Incluso llegó a decir que una mujer con pensión podía considerarse económicamente dependiente de su marido, aunque no trabajaba, pero tenía ahorros con los que ambos cubrían sus necesidades y requerimientos comunes $^{52}$.

En cambio, si una persona está sometida a un régimen de internado con asistencia gratuita, por el que el Estado cubre las necesidades básicas de subsistencia, "vivienda y vestido", no puede considerarse económicamente dependiente, aunque sea hijo del causante ${ }^{53}$.

En definitiva, la cláusula general de dependencia económica debe interpretarse en el sentido de que existe tal condición cuando una persona se encuentra en situación de vulnerabilidad económica porque no puede, independientemente de que tenga ingresos o una pensión, satisfacer todas sus necesidades de forma independiente, y esas necesidades son satisfechas permanentemente por o con la ayuda de otra persona.

\section{LA PROTECCIÓN DE LOS HEREDEROS ESPECIALMENTE PROTEGIDOS}

El derecho civil cubano, como todos los ordenamientos jurídicos que prevén la protección de los herederos especialmente protegidos, debe establecer no solo los presupuestos de hecho, sino también los medios de protección adecuados. En el derecho cubano la legítima está protegida tanto cualitativa como cuantitativamente.

Se habla de protección cualitativa cuando se dirige a impedir que la legítima esté gravada con cargas o gravámenes que pueden reducir su valor o minorar el importe pecuniario de la legítima, y de protección cuantitativa cuando trata de paliar que el heredero especialmente protegido ha recibido, en concepto de legítima, menos de la cuota que le corresponde por ley.

El amparo cualitativo de la legítima está regulado por la norma del art. 492 apartado 2. c.c., que establece que el testador no puede imponer ningún gravamen o condición ${ }^{54}$ a la legítima.

La protección cuantitativa de la legítima está regulada en el artículo 494 del Código Civil, que establece que el heredero especialmente protegido lesionado en la cuantía de su legítima puede pedir el complemento de la legítima, y en el artículo 495, que regula el caso de la preterición del heredero especialmente protegido. Ambas normas atañen a la protección cuantitativa de la legítima, 
pero parten de premisas diferentes: la primera trata del caso de un heredero especialmente protegido que haya recibido algo, aunque sea menos de lo que le corresponde, mientras que la segunda trata del caso de preterición total del heredero especialmente protegido.

El ordenamiento jurídico cubano, a través de este conjunto de normas, protege a quienes, en el momento del fallecimiento del causante, pueden ser considerados herederos especialmente protegidos y les permite conseguir la mitad de la herencia. Las acciones de protección son, en primer lugar, la impugnación del testamento, o más exactamente, de las disposiciones testamentarias que vulneran la legítima. Por esta razón, no es raro -y de hecho sería aconsejableque el testamento contenga una cláusula de salvaguarda general ${ }^{55}$, por la que el testador les asigna, en caso de que haya herederos especialmente protegidos a su muerte, lo que les corresponde conforme a la ley ${ }^{56}$.

\subsection{La protección cualitativa de la legítima}

La disposición del artículo 492, párrafo 2, del Código Civil establece que el testador no puede imponer ningún gravamen sobre la legítima.

Esta regla es una expresión del principio de intangibilidad cualitativa de la legítima: quiere impedir que el heredero especialmente protegido, por razón del gravamen o de la condición, obtenga bienes de un valor económico inferior a la cuantía que le corresponde. Esta norma obliga a establecer: 1) qué debe entenderse por gravamen; b) cuál es el remedio; c) si hay excepciones.

La palabra "gravamen" es utilizada de forma genérica y no técnica, de modo que puede incluir no sólo cualquier carga que pueda imponerse sobre la legítima, sino, de forma más general, cualquier disposición que tenga por objeto o por efecto una reducción de la cuantía de la legítima, o un menoscabo de la forma de adquisición. Desde este punto de vista, no sólo debe considerarse un gravamen toda obligación que limite la ventaja patrimonial, sino también el plazo. En palabras de PÉREZ GALLARDO: «la palabra gravamen tiene el significado de comprender cualquier modo, limitación, impedimento, sea este de naturaleza real o personal, que de alguna forma restrinja o merme el pleno disfrute y disponibilidad de lo asignado por legítima o cree cualquier obligación en relación con ella» ${ }^{57}$.

No cabe duda de que la norma del artículo 492.2 del Código Civil debe considerarse una norma imperativa. Esto significa que el gravamen impuesto por el testador debe considerarse ineficaz. Sin embargo, creo que, al tratarse de una norma puesta en el interés del heredero especialmente protegido, es importante que la decisión sobre la ineficacia recaiga en él, en cuanto único interesado. En este sentido me parece correcto afirmar que el gravamen impuesto por el testador es ineficaz ipso iure, precisando, sin embargo, que siempre es necesaria una manifestación de voluntad en ese sentido por parte del interesado. La mera existencia de gravámenes que pesan sobre la legítima no es suficiente para producir la ineficacia de la disposición testamentaria ut sic, sino un hecho capaz de otorgar al heredero especialmente protegido la facultad de pedir que se considere ineficaz.

Según esta interpretación, el gravamen con el que el testador ha mermado la legítima es ineficaz ipso iure, en el sentido de que la ineficacia es independiente de una sentencia (que, en caso de litigio, sólo tendría carácter declarativo), y requiere la voluntad de la persona interesada. Es decir, es necesario que el heredero especialmente protegido, incluso extrajudicialmente, manifieste su 
voluntad para dejar sin efecto el gravamen. En ausencia de esta manifestación de voluntad, la disposición debe considerarse perfectamente válida y eficaz.

Por último, la norma del apartado 2 del artículo 492 del Código Civil se aplica únicamente en el caso de que el gravamen sea impuesto directamente por el testador y no cuando se trate de gravamen impuesto por la ley. En este sentido, no puede considerarse sujeto a esta regulación el derecho de los ocupantes no herederos "a mantener la ocupación de la vivienda" tras el fallecimiento del propietario, regulado en el art. 77.4 de la Ley General de la Vivienda ${ }^{58}$.

Existe una diferencia entre la protección cualitativa del art. 492.2 del Código Civil y la disciplina de la reducción de las disposiciones testamentarias y las donaciones inoficiosas ${ }^{59}$.

Para que la norma del art. 492.2 del Código Civil sea aplicable, es necesario y suficiente que el heredero especialmente protegido sea instituido heredero sólo en la legítima y que ésta esté sujeta a cualquier gravamen, que sea impuesto inmediata y directamente por el testador. Es necesario que se den las dos condiciones, ya que la ausencia de una sola de ellas excluye la aplicabilidad de la norma contenida en el artículo 492.2 del Código Civil y lleva a considerar que hay una mera lesión de la legítima y que el heredero especialmente protegido solo puede pedir el complemento.

Se puede discutir la aplicabilidad de la norma del artículo 492.2 del Código Civil en el caso de que el heredero especialmente protegido se instituya como heredero en una parte alícuota mayor que la legítima y exista un gravamen que afecte también a la legítima. En este caso, aunque se podría pensar que no se puede aplicar esta norma y que, en cambio, es necesario demandar la reducción, creo que hay que preferir la solución contraria. El gravamen debe considerarse efectivo únicamente en la parte que exceda la legítima, mientras que tiene que considerarse ineficaz ipso iure (según lo dicho) por la parte que afecta a la legítima. Asumir que el heredero especialmente protegido deba, en este caso, pedir la reducción de la disposición testamentaria no parece razonable, además porque acabaría dando al testador un medio cómodo para evitar la aplicación de la norma del art. 492.2 del Código Civil. El testador que quisiera evitar la aplicabilidad del art. 492.2 del Código Civil podría, de hecho, instituir a los herederos especialmente protegidos en una parte alícuota superior a la legítima (por ejemplo, 2/3), imponiendo un gravamen capaz de anular o eliminar la atribución patrimonial. Si en este caso el heredero especialmente protegido no pudiera actuar con el remedio establecido en el artículo 492.2 del Código Civil y tuviera que solicitar el complemento de la legítima, se eludiría sustancialmente el ámbito aplicativo de la norma.

\subsection{Protección cuantitativa de la legítima}

La disposición del artículo 494 del Código Civil establece que el heredero especialmente protegido al que el testador haya dejado, por cualquier motivo, menos de lo que le corresponde, tiene derecho a pedir el complemento de la legítima.

El requisito para la aplicación de la norma es que el heredero especialmente protegido haya recibido bienes del testador, pero que no sean suficientes. No es necesario, como aclara la expresión "por cualquier título", que el causante haya dejado al heredero especialmente protegidos bienes a título de herencia o legado, pues son relevantes a este respecto también las donaciones y liberalidades realizadas por el causante durante su vida.

Como ha aclarado lúcidamente ALFARO GUILLÉN" ${ }^{60}$ "el complemento" no indica una acción jurídica, sino una finalidad. El derecho al complemento es un derecho subjetivo que corresponde 
al heredero especialmente protegido que ha recibido menos de su legítima y se ejerce mediante un conjunto de facultades impugnatorias que dependen del tipo de lesión.

No debemos, por tanto, confundir el derecho al complemento, que es un derecho subjetivo del heredero especialmente protegido, con las acciones a través de las cuales el heredero especialmente protegido puede obtener el complemento, que son las acciones de reducción, rescisión, inclusión e inclusive colación ${ }^{61}$. Es decir, un conjunto de acciones tendentes a dejar sin efecto los actos o negocios jurídicos que lesionan la legítima, para que el heredero especialmente protegido consiga lo que le corresponde en concepto de legítima.

Aclarada la diferencia entre el derecho al complemento y las acciones por las que se realiza el complemento, hay que decir que el ordenamiento jurídico cubano no dicta una disciplina orgánica sobre las acciones de reducción, por lo que al margen de lo que leemos en el art. 378, apartado a) del Código Civil, la reconstrucción conceptual es doctrinaria y, obviamente, toma mucho del derecho español que, como es sabido, estaba sustancialmente vigente en la Isla, antes de la aprobación del Código Civil actualmente vigente.

Considerar el complemento de la legítima un derecho subjetivo que corresponde al heredero especialmente protegido ayuda a aclarar algunos aspectos importantes sobre la legitimación activa, la legitimación pasiva, el objeto del derecho y su naturaleza.

La legitimación activa corresponde al heredero especialmente protegido lesionado, es decir, que ha recibido, en concepto de legítima, menos de lo que le corresponde, mientras que el sujeto pasivo será el beneficiario de la atribución que determina la lesión.

En cuanto a la naturaleza del derecho, se trata de un derecho personal, ya que la acción no se refiere al bien, sobre el que el heredero especialmente protegido no tiene ningún poder, sino al acto o negocio jurídico que determina la lesión de la legítima, que el interesado debe impugnar. Declarada la ineficacia del negocio jurídico, el bien vuelve al patrimonio del causante y el heredero especialmente protegido, por su cualidad ${ }^{62}$, puede pedir su restitución. El carácter real no es propio del derecho al complemento en sí mismo, sino de la restitución que el heredero especialmente protegido puede pedir una vez declarada la inoficiosidad del negocio jurídico lesivo.

El título en virtud del cual el heredero especialmente protegido adquiere el bien no es el derecho al complemento, ni la acción para hacer inoficioso el negocio jurídico perjudicial, sino el título de heredero especialmente protegido.

Las acciones legales por las que el legitimario puede satisfacer el derecho a obtener el complemento son las siguientes ${ }^{63}$ :- reducción/nulidad de la institución del heredero;- reducción/ nulidad de legados;- reducción/nulidad de los actos de adjudicación hereditaria en perjuicio de la legítima;- reducción/nulidad de las donaciones, incluidas las donaciones simuladas o fraudulentas realizadas en detrimento de la legítima ${ }^{64}$.

Es controvertible si las disposiciones testamentarias deben reducirse todas juntas, como establece el derecho italiano ${ }^{65}$, o si se reducen primero las disposiciones testamentarias y luego los legados, como establece el derecho español ${ }^{66}$. A favor de esta última solución parece estar la norma del artículo 495 del Código Civil cubano que, en referencia al caso de preterición, establece que primero deben reducirse las disposiciones testamentarias y solo después los legados.

Aunque el ámbito de aplicación de ambas normas es diferente, razones de coherencia sistemática y razones históricas sugieren que el orden de reducción establecido en la norma en materia de preterición debe considerarse también aplicable al caso del derecho al complemento y, por tanto, afirmar que primero debe realizarse la reducción de las instituciones de herederos y después la 
reducción de los legados. Estos últimos deben reducirse proporcionalmente, mientras que no es posible que el heredero especialmente protegido opte por impugnar solo una de ellas ${ }^{67}$.

Por otra parte, no se discute que la reducción de las liberalidades y otros actos entre vivos debe realizarse después de la reducción de las disposiciones testamentarias.

En este sentido, también hay que afirmar que las donaciones no deben reducirse todas al mismo tiempo y de forma proporcional, ya que la reducción debe comenzar por la más reciente, retrocediendo gradualmente hasta la más antigua. Esto se justifica considerando que, ante una pluralidad de actos realizados por el causante, el que genera la lesión es el último.

Es necesario repetir que la acción de reducción de los actos y negocios jurídicos lesivos de la legítima determina su ineficacia. La ineficacia de una institución de heredero es diferente de la ineficacia de los legados o de las donaciones.

La primera implica la ineficacia de una institución de heredero, con la consecuencia de que la parte de la herencia que queda vacante se defiere al heredero especialmente protegido. La cuestión si esta devolución tiene lugar bajo las normas que rigen a los herederos especialmente protegidos o bajo las normas que rigen la sucesión intestada. Personalmente sería partidario de la segunda teoría, precisamente porque en los sistemas jurídicos en los que la protección de los herederos especialmente protegidos actúa como freno o limitación a la libertad testamentaria, la legítima no constituye un tipo de sucesión autónoma y distinta de la sucesión intestada y/o testamentaria. Al margen de esta difícil cuestión, no cabe duda de que la parte alícuota de la herencia que queda vacante, como consecuencia de la ineficacia de la institución de heredero, corresponderá, bien según la sucesión intestada, bien según la sucesión necesaria, al heredero especialmente protegido. La condición de heredero le permite adquirir los bienes correspondientes y si éstos ya están en posesión de otros (el heredero cuya institución ha sido declarada ineficaz), ellos deberán entregárselos inmediatamente. Debe quedar claro que la reducción de la institución de heredero sólo determina la inoficiosidad y no la adquisición de los bienes hereditarios, que sí se adquieren en virtud del título de heredero.

La reducción de los legados y/o donaciones determina también su ineficacia, con la consecuencia de que los legados y las donaciones quedan sin efecto con la consecuencia de que los bienes objeto del legado o de la donación se consideran como si nunca hubiera salido del patrimonio del causante. El heredero especialmente protegido no adquiere los bienes objeto de los legados y donaciones por efecto inmediato y directo de la acción de reducción, sino en virtud de su título de heredero. Por eso se dice que la acción de reducción produce el efecto inmediato y directo de la ineficacia del acto. Esto último determina, a su vez, como efecto reflejo, que el heredero especialmente protegido pueda adquirir la titularidad de ese bien. En este sentido se puede hablar de efectos inmediatos y efectos mediatos o, también, de efectos preliminares y efectos definitivos. El efecto preliminar es la inoficiosidad del acto dispositivo que merma la legítima; el efecto definitivo es la adquisición de la propiedad por parte del heredero especialmente protegido.

\subsection{La preterición del heredero especialmente protegido}

La última norma dedicada a la protección cuantitativa de la legítima es el artículo 495 del Código Civil, que regula la hipótesis específica de la preterición del heredero especialmente protegido.

El principal problema que subyace a esta norma es el de definir su ámbito de aplicación, pues es importante establecer cuándo el heredero especialmente protegido debe ejercitar la acción de 
complemento de la legítima ex art. 494 Código Civil y cuándo, en cambio, debe ejercitar la acción de preterición ex art. 495 Código Civil.

La norma en cuestión no define su presupuesto aplicativo, a saber, el de la preterición. Para entender correctamente lo que significa, es indispensable tener en cuenta dos conceptos clave: la mención y la atribución ${ }^{68}$.

El primer requisito necesario e indispensable para la existencia de una preterición es que el heredero especialmente protegido no sea mencionado en el testamento o, más exactamente, que el testador no lo haya instituido como heredero. Si lo ha mencionado, pero no lo ha instituido heredero, debe considerarse pretérito, según la hipótesis conocida como omisión material ${ }^{69}$.

En la hipótesis de que el heredero especialmente protegido se estableciera como heredero, no puede haber preterición. Esto significa que, por definición, la preterición sólo puede darse en el caso de una sucesión enteramente testamentaria, ya que, en caso de sucesión intestada, aunque parcial, el herederso especialmente protegido será ciertamente heredero ${ }^{70} \mathrm{y}$, por tanto, faltaría el presupuesto de su preterición ${ }^{71}$.

Para que haya preterición no basta con que la persona no sea mencionada en el testamento como heredera, sino que es necesario que no haya sido destinataria de ninguna atribución patrimonial, a título de legado o inter vivos.

Como es bien sabido, el ordenamiento jurídico cubano protege a los herederos especialmente protegidos asignándoles la mitad del haber hereditario, de modo que el principal interés es que consigan, por cualquier concepto, bienes correspondientes a su cuota ${ }^{72}$. Tanto es así que, si un heredero especialmente protegido no es mencionado en el testamento, pero ha recibido la legítima en vida, no podrá reclamar nada. Además, está claro que se trata de una norma sobre la protección cuantitativa de la legítima.

Si el heredero especialmente protegido no se menciona en el testamento, pero es destinatario de una atribución, no puede ser considerado preterido, por lo que tendrá que ejercitar la acción de complemento ex artículo 494 del Código Civil.

La preterición puede ser intencionada o involuntaria, dependiendo de si existe un propósito por parte del testador de excluir al heredero especialmente protegido, o de si falta dicho propósito ${ }^{73}$. Con referencia a este último caso, basta pensar en el caso de un testador que desconoce la existencia de un heredero especialmente protegido, por ejemplo, un hijo, que no sabía que tenía y que sólo después de su muerte pide la comprobación de la relación parental.

La regulación cubana no especifica qué se entiende por preterición, en cambio identifica con cierta precisión cuáles son sus consecuencias jurídicas.

En caso de preterición se anula la institución de herederos contenida en el testamento. No se trata de una acción de reducción en el verdadero sentido de la palabra, sino de una nulidad, que sólo afecta a la institución de heredero y no al testamento en su conjunto ${ }^{74}$.

La parte de herencia que ha quedado vacante por la anulación de la institución de heredero se defiere al heredero especialmente protegido para que él pueda conseguir la legítima que le corresponde $^{75}$. Aunque la norma se limita a decir que la preterición "anula la institución de heredero", hay que suponer que hay una anulación de la institución de heredero limitada a lo necesario para que el heredero especialmente protegido consiga su legítima. 
Esta interpretación se justifica si se tiene en cuenta que la protección de los herederos especialmente protegidos constituye una disciplina excepcional y que la preservación de la voluntad testamentaria es, sin embargo, un principio fundamental del derecho cubano.

Un ejemplo ayuda a entenderlo. Imaginemos que: a) el testador ha instituido como herederos a los dos amigos Fulano y Mengano; b) su propio patrimonio vale 200 y consta de dos bienes, cada uno de los cuales vale 100; c) en la fecha de su muerte se constata que hay un hijo que cumple los requisitos para ser considerado heredero especialmente protegido; d) que el hijo no fue mencionado en el testamento, ni recibió ninguna atribución patrimonial de su padre.

No hay duda de que se produce en este caso un supuesto de preterición. Sin embargo, no sería correcto suponer que las instituciones de heredero deben anularse en su totalidad, sino que debe anularse sólo en parte, es decir, en la medida necesaria para que el hijo consiga la legítima. Considerando que la legítima es igual a 100 (1/2 del caudal hereditario), las instituciones hereditarias a favor de Fulano y Mengano deben ser anuladas en parte, es decir, cada una por $1 / 2$, con la consecuencia de que tras la anulación: Fulano será heredero por 1/4, Mengano será heredero por $1 / 4$ y el hijo heredero por $1 / 2$. Si se anularan las instituciones de los herederos en su totalidad, se llegaría a una solución poco razonable, porque el heredero especialmente protegido obtendría mucho más que la parte legítima, sin lograr la conservación de la voluntad testamentaria.

El artículo 494 del Código Civil establece que los legados que no excedan de la parte de los bienes de los que el testador pueda disponer, siguen siendo válidos. De esta disposición se desprende que la anulación de los legados sólo opera tras la anulación completa de las instituciones del heredero y que todos los legados deben reducirse proporcionalmente, limitándose a lo necesario para integrar la legítima del heredero especialmente protegido.

Hay que señalar que la anulación de la institución de heredero y de los posibles legados son efectos que pueden calificarse como preliminares, ya que sólo sirven para anular la institución de heredero o los legados. Las consecuencias relacionadas son diferentes. En caso de anulación de una institución de heredero, una parte de la herencia queda vacante. Esto significa que habrá devolución de esta parte en favor del heredero especialmente protegido.

Existe un debate sobre si esta atribución de la cuota se produce en base a la sucesión intestada o a las normas de la sucesión necesaria. A este respecto, me inclino por la primera solución, por razones de coherencia con la idea de que la regulación de los herederos especialmente protegidos tiene la naturaleza de un freno a la libertad de testar y no constituye un tercer tipo de sucesión, diferente de intestada y la testamentaria. Es de suponer ${ }^{76}$ que las sentencias que anulan la institución de heredero no abren también la sucesión intestada porque se trata de asuntos para los que son competentes distintos jueces. Las acciones de impugnación de preterición son competencia de las Salas de lo Civil y de lo Administrativo de los Tribunales provinciales populares por los cauces del proceso ordinario, mientras que la declaración de heredero intestado es competencia de las secciones civiles de los tribunales municipales populares por los cauces del proceso sucesorio de declaración de herederos ${ }^{77}$.

La anulación de los legados determina su ineficacia, con la consecuencia de que los bienes se consideran parte de la herencia y pueden ser adquiridos por el heredero especialmente protegido en virtud de su condición de heredero. Una vez más, es posible distinguir entre los efectos preliminares, que consisten esencialmente en la ineficacia de las disposiciones testamentarias, y los efectos definitivos, que consisten en la adquisición del bien por parte del heredero especialmente protegido. 
Por tanto, las acciones de impugnación tienen el efecto inmediato y directo de dejar sin efecto las disposiciones testamentarias.

Otros efectos se derivan de la ineficacia de la disposición testamentaria, que permiten al beneficiario legítimo adquirir los bienes objeto de las disposiciones impugnadas en virtud de su condición de heredero.

Si los bienes estuvieran en manos del beneficiario de la disposición ineficaz, el heredero especialmente protegido tiene derecho a reclamar su entrega. Esto hace pensar que la acción impugnatoria es, en todo caso, una acción de carácter personal, mientras que la acción real es la restitutoria, que es posterior y solo eventual.

La norma en cuestión no menciona la reducción de las donaciones. No obstante, debe aceptarse que el heredero especialmente protegido pueda interponer una acción de reducción de las donaciones, cuando sea necesario. $\mathrm{Si}$, en caso de preterición, la anulación de todas las disposiciones testamentarias (tanto las instituciones de heredero como los legados) no es suficiente para integrar la legítima, no cabe duda de que el heredero especialmente protegido puede actuar mediante una acción de reducción de donaciones, según la disciplina del art. 378, letra a).

\section{CONCLUSIÓN}

El ordenamiento jurídico cubano reconoce el derecho a una parte del haber hereditario cuando el heredero se encuentre en una situación de vulnerabilidad económica. De hecho, son herederos especialmente protegidos el cónyuge, el hijo o los ascendientes cuando no estén aptos para trabajar y dependen económicamente del fallecido, es decir, cuando necesiten asistencia.

Sin embargo, el carácter de asistencia se refiere solo a la función de la legítima, pero no a su naturaleza y de hecho no consiste únicamente en una pensión alimenticia, sino en una cuota del caudal hereditario.

La confirmación de que no se trata de una legítima de contenido puramente asistencial la encontramos, entre otros, en el art. 492 del Código Civil, que establece que siempre es igual a la mitad del patrimonio, con independencia del número y la categoría de los herederos especialmente protegidos.

Los requisitos de la no aptitud a trabajar, entendido como la imposibilidad física o síquica del sujeto para realizar por sí mismo una labor productiva que le permita obtener remuneración, y de la dependencia econonomica del causante, entendida como la sujeción economica de una persona respecto a otra, deben existir en el momento de la apertura de la sucesión y perdurar hasta el momento de la partición de la herencia o hasta el momento en que se solicite el complemento.

La legítima está protegida cuantitativa y cualitativamente: en el primer caso a través de la norma que prohíbe poner gravámenes sobre la legítima; en el segundo caso a través del derecho subjetivo al complemento, que se ejerce mediante un conjunto de facultades impugnatorias (las acciones de reducción, rescisión, inclusión y colación) y la regulación específica de la preterición.

La regulación cubana me parece de gran interés porque ha logrado encontrar un punto de equilibrio muy interesante entre la libertad de testar y la protección de los legitimarios. No se protegen solo por la existencia del vínculo con el causante, sino en la medida en que existe una necesidad efectiva, que justifica, también en base al principio de solidaridad, la limitación a la libertad testamentaria. 


\section{BIBLIOGRAFÍA}

ALFARO GUILLÉN, Y. (2011). Delación forzosa, preterición y legítima asistencial: análisis en los ordenamientos cubano y español (I), REDUR 9, diciembre 2011, pp. 217-243.

ALFARO GUILLÉN, Y. (2011 b). Delación forzosa, preterición y legítima asistencial: análisis en los ordenamientos cubano y español (II), REDUR 9, diciembre 2011, pp. 245-269.

ALFARO GUILLÉN, Y. (2015). El régimen jurídico de la preterición en Cuba. La Habana: Ediciones ONBC.

ALFARO GUILLÉN, Y. (2018). Comentario al artículo 494. En L. B. GALLARDO, Comentario al Código Civil Cubano, Tomo IV, Derecho de sucesiones, volumen II (pp. 101-123). La Habana: Editorial Universitaria Félix Varela.

ALFARO GUILLÉN, Y. (2018). Comentario al artículo 495. En L. B. GALLARDO, Comentario al Código Civil Cubano, Tomo IV, Derecho de sucesiones, volumen II (pp. 124-162). La Habana: Editorial Universitaria Félix Varela.

ALFARO GUILLÉN, Y. (2021). Tres nociones cardinales para una efectiva protección legitimaria en los sistemas de base romana. En V. BARBA, Y L. PÉREZ GALLARDO, Los desafíos contemporáneos de la legitima hereditaria (pp. 155-191). Santiago-Chile. Ediciones Olejnik.

BARBA, V. (2015). I nuovi confini del diritto successorio. Diritto delle successioni e della famiglia, pp. 333-341.

BARBA, V. (2020). La successione dei legittimari. Napoli, Edizioni scientifiche Italiane.

BARBA, V. Y PÉREZ GALLARDO, L. B. (2021). V. BARBA, \& L. PÉREZ GALLARDO, Los desafíos contemporáneos de la legitima hereditaria. Santiago-Chile. Ediciones Olejnik.

BETTI, E. (1929). Successione legittima e necessaria, Lezioni raccolte da G. Gorla, Milano.

CICU, A. (1943). Successione legittima e dei legittimari, $2^{a}$ ed., Milano, Giuffré.

DÍEZ-PICAZO, L. y. GULLÓN, A., Sistema de derecho civil, IV, 2, Derecho de sucesiones, 12 ed., Editorial Tecnos, Madrid, 2017 (2017). Sistema de derecho civil, IV, 2, Derecho de sucesiones (12 ed.). Madrid: Editorial Tecnos.

FERRARA, F. (1923). La figura del legittimario, en Giurisprudenza italiana, 1923, IV, pp. 116-121.

FERRI, L. (1965). Dei legittimari, 2ª ed., Bologna-Roma, Zanichelli, 1981.

MARINARO, G. (2009). La successione necessaria, Napoli, Edizioni scientifiche italiane.

MENGONI, L. (2000). Successioni per causa di morte. Parte speciale. Successione necessaria, 4aa ed., Milano, Giuffré.

MESSINEO, F. (1962). Manuale di diritto civile e commerciale, vol. VI, Diritto delle successioni per causa di morte, 9 a ed., Milano, Giuffré.

PÉREZ GALLARDO, L. B. (2018). Comentario al artículo 492. En L. B. GALLARDO, Comentario al Código Civil Cubano, Tomo IV, Derecho de sucesiones, volumen II (pp. 1-37). La Habana: Editorial Universitaria Félix Varela.

PÉREZ GALLARDO, L. B. (2018). Comentario al artículo 493. En L. B. GALLARDO, Comentario al Código Civil Cubano, Tomo IV, Derecho de sucesiones, volumen II (pp. 38-100). La Habana: Editorial Universitaria Félix Varela.

PÉREZ GALLARDO, L. B. (2021). Hacia una leǵitima asistencial: Ni Escila ni Caribdis. En V. BARBA Y L. PÉREZ GALLARDO, Los desafíos contemporáneos de la legitima hereditaria (pp. 113-154). SantiagoChile. Ediciones Olejnik.

PÉREZ GALLARDO, L. B. y FERNÁNDEZ MARTELL, J.K (2016). Aplicación retroactiva de las normas civiles en la interpretación del testamento y ajuste del sistema legitimario, Revista de investigación en Derecho, 
Criminología y Consultoría Jurídica, Benemérita Universidad Autónoma de Puebla, México, Año 10, N.19, abril-septiembre 2016, pp. 227-260.

PERFETTI, U. (2020). Dei legittimari, Bologna-Roma, Zanichelli.

RIVAS MARTÍNEZ, J. J. (2009). Derecho de sucesiones. Común y foral, II (4 ed.). Madrid: Dykinson.

VEGA CARDONA, R. J. Y PANADERO DELLA CRUZ, E. (2011). Las donaciones colacionables: el enigma de una institución jurídica. Incidencias sustantivas para el derecho positivo cubano, Jurídicas, Vol. 8, №. 1, pp. $13-44$

VEGA CARDONA, R. J. Y PANADERO DELLA CRUZ, E. (2015). «El cálculo de la cuota reservada a los especialmente protegidos en Cuba y la protección de su intangibilidad cuantitativa. (Glosa a la sentencia n. 365 de 25 de septiembre de 2012 de la Sala de lo Civil y Administrativo del Tribunal Supremo popular)», Revista de derecho civil, 2015, 3, pp. 199-220.

VEGA CARDONA, R. J. (2016). El cómputo de las donaciones indirectas para el cálculo de la legítima. Especial examen de cuatro actos de liberalidad bajo el lente cubano. Revista de Derecho Privado, (55). Universidad de los Andes (Colombia). http://dx.doi.org/10.15425/redepriv.55.2016.10

NOTAS

1 Señala ALFARO GUILLÉN, Y. (2011 b), p. 264, que «"Sistema legitimario" es el modo en el que cada ordenamiento concibe la dinámica de la legítima, atendiendo a su aspecto funcional, a su contenido, a su aspecto formal o material y a su cuantía o extensión».

2 PÉREZ GALLARDO, L. B. (2018). Comentario al artículo 493, p. 48, precisa que en el derecho español es suficiente una relación familiar o conyugal. «No resulta así en el ordenamiento cubano en el que tales vínculos no son suficientes, aunque sí necesarios. El legislador ha añadido un plus que tiene un profundo contenido ético, social, humanista, tuitivo, asistencial y que se compatibiliza muy bien con la tendencia a ampliar la libertad de testar en el orden subjetivo, sin desdén de precautelar los derechos de las personas verdaderamente necesitadas, lo que es palpable en el animus de nuestro legislador».

3 Sentencia de lo Alto foro 30 de abril de 2013, n. 178, «se aprecia que por el articulo cuatrocientos noventa y tres inciso uno del Código Civil se establece como requisitos para ser considerado heredero especialmente protegido que la persona de que se trate no esté apto para trabajar y que dependa económicamente del testador; circunstancias que ha de concurrir de conjunto, en tanto, si faltara una de ellas no se alcanzaría esa especial condición; relacionándose en el propio precepto con posibilidad a alcanzar esa categoría, a lo hijos o sus descendientes siempre que hubieren premuerto los primeros, el cónyuge sobreviviente y los ascendientes; en el caso está probado y así quedó establecido». «Que la actora estaba casada legalmente con el testador, que no estaba vinculada al trabajo pero además que al momento de fallecer su esposo concurría en la misma inaptitud para trabajar esencialmente por razón de la edad, pues contaba entonces con sesenta y seis años; todo ello, unido a la dependencia económica del testador, lo que incluso motivó que le fura concedida pensión por la Seguridad Social como viuda del mismo; de donde, al concurrir en su persona las condiciones que se exigen por el precepto legal antes mencionado, no cabe dudar que la misma debe ser considerada heredera especialmente protegida de su fallecido marido».

4 Se puede debatir si los herederos especialmente protegidos deben ser considerados legitimarios o no. La elección del lenguaje realizada por el sistema jurídico cubano, quizás también por la influencia del derecho soviético, debería llevar a pensar que existe una diferencia sustancial. Sin embargo, debe señalarse que según la mejor doctrina cubana (PÉREZ GALLARDO, L. B. (2018). Comentario al artículo 492, pp. 17-22; PÉREZ GALLARDO, L. B. (2018). Comentario al artículo 493, pp. 49-61; ALFARO GUILLÉN, Y. (2018). Comentario al artículo 494, pp. 105-108) los herederos especialmente protegidos deben ser considerados verdaderos legitimarios, y esto constituye, en efecto, uno de los argumentos más significativos de la mejor doctrina, que ofrece una amplia prueba de que la "porción de la herencia que corresponde a los herederos especialmente protegidos" cubana debe ser considerada una legítima (ver nota al pie n. 8). Además, hay que añadir que en la jurisprudencia cubana y especialmente en la del Tribunal Supremo, que he tratado de resumir en este trabajo, en muchas ocasiones no se duda en definir a los herederos especialmente protegidos como "legitimarios" (véase al 
respecto la jurisprudencia citada en las siguientes notas: 44, 51) y la porción de herencia que a ellos le corresponde como "legitima (véase al respecto la jurisprudencia citada en las siguientes notas: 44, 56). Más allá del nombre de la institución, no cabe duda de que se trata de una normativa que sirve para dar protección patrimonial a determinadas personas por sus vínculos familiares con el fallecido. A diferencia de los sistemas más tradicionales, la relación familiar por sí sola no es suficiente, sino que deben cumplirse otros dos requisitos (no aptitud para trabajar y dependencia económica del causante). Es discutible que estos elementos conduzcan a la exclusión de los legitimarios en sentido estricto, pero para ello habría que comprobar también si, desde el punto de vista de la teoría general del derecho, independiente de los distintos ordenamientos jurídicos, existe o no un concepto apriorístico de legítima y/o legitimarios o si estas expresiones sirven para indicar, con todos los matices posibles de cada ordenamiento jurídico, un sistema de protección patrimonial de determinados parientes del fallecido, a los que se reservan derechos sucesorios patrimoniales. Es difícil establecer, en términos teóricos, cuáles deben ser las características de una regulación para que sea calificada en términos de "legítima" y los sujetos protegidos en términos de "legitimarios". Si el rasgo calificativo es sólo la protección patrimonial de determinados miembros de la familia, entonces desde un punto de vista teórico la regulación cubana también debería considerarse como tal, mientras que, si el rasgo calificativo es también la atribución de esta cualidad con independencia de la condición de las personas, entonces es evidente que la disciplina cubana debería ser sacada. Me parece que desde un punto de vista puramente teórico (para un análisis de diversos sistemas de sucesión necesaria, véase BARBA, V. Y PÉREZ GALLARDO, L. B. (2021), p. 3 ss.), siempre que se quiera admitir la admisibilidad de un concepto meta-normativo de legítima, que pueda resumirlos todos, el rasgo calificativo debería ser únicamente la protección patrimonial específica de determinados parientes del causante. Sobre la base de estas consideraciones, aunque consciente de que desde un punto de vista conceptual el Código civil cubano no hace referencia específica a la legítima, sino a la "porción de la herencia que le corresponde"; no hace referencia a los legitimarios, sino a los "herederos especialmente protegidos", en el transcurso de este trabajo, también en aras de simplicidad, voy a utilizar también la expresión "legítima" o "legitimarios". Por último, pero no por ello menos importante, esta elección encuentra también una justificación sustancial, ya que, compartiendo la posición expresada por la mejor doctrina (PÉREZ GALLARDO, L. B. (2018). Comentario al artículo 493, pp. 49-51), creo, aunque con todas las aclaraciones y matizaciones necesarias que el tema merece, que podemos compartir la idea de que la protección de los herederos especialmente protegidos se corresponde con la protección de los legitimarios y que cambia, no tanto el mecanismo técnico jurídico de la protección de los herederos especialmente protegidos, sino los requisitos previos a la concurrencia de los cuales el sujeto puede ser considerado un heredero especialmente protegido. Para finalizar, me parecen muy ilustrativas al respecto las palabras de PÉREZ GALLARDO, L. B. (2018). Comentario al artículo 493, p. 49 s., «Algunos operadores del derecho, dejándose llevar por el continente, tras obviar el contenido, afirman la inexistencia en el ordenamiento cubano de la figura de los legitimarios, porque no hay legítima... Que el legislador cubano quizás pensó en un ordenamiento sucesorio al que le fuera ajeno la figura de la legítima, puede ser cierto. Que tras la vigencia del Código Civil cubano operaron importantes cambios en la forma de concebir los legitimarios, también es ciero, pero tampoco al extremo de catalogar estos cambios como sustanciales. La trasformación fue más aparente que verdadera. Se acudió más a cambiar el nombre por el que fueron conocidos los perceptores de uan parte del patrimonio del causante (legitimarios) y la porción dstinada a ellos (legítima) que a mutar su esencia, la que en principio se mantuvo impertérrita, salvo el profundo contenido axiológico que le fue dotado, y que hace más ductil esta institución». PÉREZ GALLARDO, L. B. (2021), p. 136 ss.

BARBA, V. (2015), p. 340.

BARBA, V. (2020), p. 19 ss.; MARINARO, G. (2009), p. 26 ss.; PERFETTI, U. (2020), p. 12 ss.

BARBA, V. Y PÉREZ GALLARDO, L. B. (2021), pp. 113 ss., 195 ss., 219 ss., 241 ss., 265 ss., 279 ss., 299 ss. ALFARO GUILLÉN, Y. (2011), p. 218 ss.

9 Las expresiones "porción del caudal hereditario que corresponde" y "legítima", que hoy utilizamos de forma casi equivalente, tienen una implicación conceptual muy diferente y atestiguan el distinto significado de la disciplina de la sucesión necesaria en los sistemas romano y germánico-francés. Véase BETTI, E. (1929), p. 4 Ss. En el sistema romano, los legitimarios tenían derecho a ser instituidos como herederos, salvo que existieran hipótesis que justificaran su desheredación por ingratitud, pero sobre todo tenían derecho a recibir una parte del haber hereditario, independientemente del título de la herencia. La segunda se refiere a la cuota de reserva, entendida como una auténtica cuota de la herencia, es decir, como pars hereditatis. Para entender este sistema, hay que tener en cuenta que el testamento, en parte debido al principio de copropiedad familiar existente (en 
virtud del cual existía una comunión familiar tácita de bienes de la que el padre era mero administrador), sólo servía para ordenar legados y que la libertad de testar sólo se permitía en parte. Para una reconstrucción concisa y clara de los dos sistemas, véanse, por ejemplo, FERRARA, F. (1923), pp. 116-121; MESSINEO, F. (1962), p. 291. En Italia, esta tesis fue apoyada por Cicu. Sin embargo, ha quedado aislado y Mengoni ha demostrado su falacia. Según CICU, A. (1943), pp. 3 ss., 143 ss., la ley garantiza al legitimario tanto una parte de la herencia, igual a la parte de los bienes que el ordenamiento jurídico reserva al legitimario, como una parte de los bienes, igual a la realización del valor de la cuota de reserva. Como señala el autor «chiameremo la prima quota ereditaria o quota riservata; la seconda legittima o quota di legittima. L'avvertimento è necessario perché altrimenti non si distingue tra l'una e l'altra». Partiendo de esta premisa y partiendo de la base de que el interés familiar prima sobre cualquier otro interés del testador, el Autor afirma que el legitimario es heredero ipso iure, es decir, que el legitimario debe considerarse nombrado heredero en una porción igual a la parte de patrimonio reservado, inclusive en presencia de disposiciones testamentarias que no lo contemplen como heredero. El autor lo aclara en la p. 165 ss. «la distinzione fra quota ereditaria e quota di legittima ci pare chiarisca anche questo. La quota ereditaria, appunto perché tale, e senz'altro devoluta al legittimario: per conseguirla egli non ha bisogno di agire in riduzione; basta che accetti. Si deve cioè a parer nostro ritenere che se ad es. il testatore che abbia un figlio, istituisca erede universale un estraneo, l'eredità si devolva per metà al figlio per metà all'estraneo (salvo vedere se, cedendo la delazione a favore del figlio, acquisti pieno vigore la delazione universale o si apra invece la successione legittima nella quota) [... ] viene cosí a riconfermarsi l'opinione che la successione del legittimario sia successione legittima potenziata. E a lui devoluta per legge una quota dell'asse ereditario (relictum), per cui non può il testatore disporre che della quota residua (quota disponibile). II nostro sistema si presenta cosí piú chiaramente come il risultato della fusione dei sistemi romano e germanico-francese». MENGONI, L. (2000), p. 61, a partir de una investigación histórica, aclara el error de la perspectiva de Cicu, que tiende a atribuir a la cuota reservada una razón autónoma con respecto a la legítima, y demuestra que hoy la ley reserva a los parientes una cuota de la herencia porque no quiere tanto que sean herederos, sino que obtengan una cierta parte de los bienes del difunto (legítima) y para ello les proporciona el título de heredero, el único capaz de ofrecer una protección más fuerte que el simple derecho de crédito.

11 MENGONI, L. (2000), p. 44 ss., señala que el significado y el modo de operar de las normas sobre la legítima en el caso de la sucesión intestada y de la sucesión testamentaria son muy diferentes, por lo que es imposible resumir la función de las normas sobre la reserva en una función única y unitaria.

RIVAS MARTíNEZ, J.J.(2009), p. 1405-1460, teniendo en cuenta el contenido de la legítima, afirma que e pueden proponer seis tipos diferentes: a) legítima como pars hereditatis (la ley atribuye al legitimario la condición de heredero); b) legítima como pars valoris (la ley otorga al legitimario un derecho de crédito simple, que se paga en dinero); c) legítima como pars valoris bonorum (la ley atribuye un derecho de crédito, que goza de una causa legítima de prelación sobre uno o varios bienes hereditarios); d) legítima como pars valoris bonorum qua in specie heres solvere debet (la ley atribuye un derecho de crédito, que goza de una causa legítima de prelación sobre uno o varios bienes hereditarios y el derecho de crédito del legitimario debe satisfacerse con bienes hereditarios y no con dinero); e) legítima como pars bonorum (la ley considera al legitimario como copropietario de los bienes de la sucesión, de modo que el legitimario es un destinatario legal de esos bienes, si su legítima no ha sido satisfecha de otra manera); f) legítima puramente simbólica (la ley exige cualquier atribución de bienes al legitimario, incluso si no tiene valor económico). Es difícil determinar a qué clasificación deben adscribirse los diferentes ordenamientos jurídicos. En lo que respecta al derecho común español, según el Autor -pero la opinión es controvertida- el contenido del derecho que corresponde a los legitimarios impone considerar la legítima como pars bonorum. En lo que respecta al derecho italiano, de acuerdo con lo que he argumentado en el texto, sostengo que la legítima, teniendo en cuenta el contenido del derecho que corresponde a los legitimarios, debe ser considerado como pars valoris bonorum qua in specie heres solvere debet, especificando que la reforma propuesta del Código Civil transformaría la legítima en pars valoris bonorum.

13 Hay ordenamientos jurídicos que atribuyen una legítima sólo por la relación familiar existente con el causante, sin más, otros ordenamientos que atribuyen la legítima sólo en caso de necesidad; otros ordenamientos que consideran la relación, pero también su duración. Además, hay ordenamientos jurídicos en los que la legítima es fija, otros en los que es variable y otros en los que, dentro de la legítima, es posible una distribución diferente entre las personas. Aun así, hay sistemas que valoran más la solidaridad familiar y permiten explícitamente la desheredación, mientras otros que, en cambio, la excluyen terminantemente. V. BARBA, V. (2020), p. 20 ss.

14 Así, PÉREZ GALLARDO, L. B. (2018). Comentario al artículo 492, p. 18 s., «La legítima cubana, atendiendo al contenido del derecho, es pars bonorum, el especialmente protegido o legitimario es un cotitular, condómino o 
copropietario de los bienes del activo hereditario, es un atributario de una cuota de bienes o una parte alícuota del patrimonio hereditario del causante, y como tal, comunero en el estado de indivisión hereditaria, hasta tanto no se le satisfaga la legítima». También, ALFARO GUILLÉN, Y. (2018), Comentario al artículo 494, p. 105.

PÉREZ GALLARDO, L. B. y FERNÁNDEZ MARTELL, J.K (2016), p. 243, «cabe también apuntar su naturaleza transitoria. Las circunstancias que cualifican la condición de legitimario asistencial, son por regla general transitorias, como lo es la minoridad o como lo pueden ser ciertas discapacidades o la situación de dependencia o vulnerabilidad económica».

16 En sentido critico, VEGA CARDONA, R.J. Y PANADERO DELLA CRUZ, E. (2015), p. 217, «La fórmula para cálculo se encuentra regulada en la generalidad de los códigos civiles y posee como operaciones: la determinación del activo bruto, la detracción del pasivo hereditario y la computación de las liberalidades realizadas por el de cuius ya fuese a legitimarios o a extraños. Empero, tales aspectos fueron excluidos expresamente por el legislador del Código Civil cubano, a pesar de que en materia de defensa de la intangibilidad cuantitativa de la condición de especialmente protegido en Cuba resulta un imperativo su realización. El legislador del Código Civil descartó la fórmula para determinar la cuota reservada por ley a los especialmente protegidos en Cuba, lo que genera en ocasiones un estado de vulneración de los derechos, al no aportarse mecanismos certeros a los operadores jurídicos para reconstruir el patrimonio del testador. Esto ha conllevado a la inobservancia de las normas imperativas que rigen el instituto, así como la indebida interpretación de la normativa legal, particularmente en los procesos de preterición y en los que se ejercita la acción de complemento».

17 Hay una diferencia con el sistema jurídico francés, en el que la reunión ficticia requiere primero sumar el relictum y el donatum y luego restar el debitum. Cfr. art. 922, Code civil, «La réduction se détermine en formant une masse de tous les biens existant au décès du donateur ou testateur. Les biens dont il a été disposé par donation entre vifs sont fictivement réunis à cette masse, d'après leur état à l'époque de la donation et leur valeur à l'ouverture de la succession, après qu'en ont été déduites les dettes ou les charges les grevant. Si les biens ont été aliénés, il est tenu compte de leur valeur à l'époque de l'aliénation. S’il y a eu subrogation, il est tenu compte de la valeur des nouveaux biens au jour de l'ouverture de la succession, d'après leur état à l'époque de l'acquisition. Toutefois, si la dépréciation des nouveaux biens était, en raison de leur nature, inéluctable au jour de leur acquisition, il n'est pas tenu compte de la subrogation. On calcule sur tous ces biens, eu égard à la qualité des héritiers qu'il laisse, quelle est la quotité dont le défunt a pu disposer».

18 VEGA CARDONA, R.J. Y PANADERO DELLA CRUZ, E. (2015), p. 217, señala la importancia de este calculo, ya que « se configura como una operación que permite fijar el contenido cuantitativo de los derechos legitimarios mediante la reconstrucción contable del patrimonio del causante».

19 PÉREZ GALLARDO, L. B. (2018). Comentario al artículo 493, p. 48, «otra diferencia puede situarse en la cuota fija de la legítima global de la que son destinatarios los legitimarios cubanos, con independencia de la condición parental o conyugal y el número de concurrentes, a diferencia de su predecesor español que determina una cuotra legitimaria variable sobre la base del tipo de legitimario concurrente».

20 Tribunal Supremo, Sala de lo Civil y de lo Administrativo, Sentencia № 58 de 23 de marzo de 2009, segundo Considerando, ponente González García «resulta posible la impugnación de donación efectuada en vida por el causante por inoficiosa tanto si la herencia es deferida por testamento como si lo es en defecto de él por delación legal, conocida como sucesión intestada o abintestato, lo que deriva de una recta interpretación de lo que establece respecto a la colación hereditaria el artículo quinientos treinta, apartado segundo, del Código Civil, en cuanto a que en la sucesión intestada se traerá a la masa hereditaria el exceso del valor de las donaciones declaradas inoficiosas; lo que implica que en tal supuesto habrá que determinar si existen personas al deceso del donante que reúnan respecto a él los requisitos de especial protección a que se refiere el artículo cuatrocientos noventa y tres, apartado primero, del Código Civil, que en tal caso concurrirán a la sucesión intestada en el primer llamado a que se refiere el artículo quinientos catorce, apartados primero y segundo, del propio cuerpo legal, precisando si la donación efectuada comprometió la mitad del patrimonio hereditario del cual el donante no podía disponer, aun cuando en la sucesión intestada no recibirían tal mitad sino la parte alícuota correspondiente; puesto que el artículo trescientos setenta y ocho, apartado a, del referido Código, proscribe por inoficiosa aquella donación que exceda de lo que puede darse o recibirse por testamento, lo que habrá de tenerse en cuenta como una virtual e hipotética limitación observable aún cuando en definitiva el testamento no hubiere llegado a otorgarse y ello torna improcedente el fundamento en que exclusivamente se sustenta el fallo interpelado en el sentido de que no cabe reputar de inoficiosa la donación efectuada solo porque la herencia se transmitió por el llamado de la ley y no por testamento, aunque lleva razón al consignar que la institución del heredero especialmente protegido es privativa de la sucesión testada». 
Tribunal Supremo, Sala de lo Civil y de lo Administrativo, Sentencia № 232 de 24 de marzo de 2003, primer Considerando, ponente Acosta Ricart, «si bien lleva razón la recurrente en cuanto a que el Tribunal a quo omitió resolver sobre la cuestión planteada referida a la ineficacia del testamento por haberse preterido a la recurrente, quien se estima heredera especialmente protegida del fallecido, lo cierto es que la misma no aportó ninguna prueba encaminada a demostrar tener tal cualidad, pues debe señalarse que en su caso no basta con ser la cónyuge sobreviviente del mismo, sino además no estar apta para trabajar y haber dependido económicamente de aquel, de donde no probados estos extremos, la sentencia que en su lugar habría de dictarse, caso de casarse la recurrida por la omisión señalada, sería de su mismo tenor».

22 V. BARBA, V. (2020), p. 51 ss.

23 Tribunal Provincial de Ciudad de La Habana, Sala Segunda de lo Civil y de lo Administrativo, Sentencia № 27 de 30 de marzo de 2007 (Proceso Ordinario), segundo Considerando, ponente Alfaro Guillén, «no basta detentar la condición de viuda del causante, para el goce del beneficio que dispensa el estatus sucesorio de devenir heredero especialmente protegido, lo que podrá verificarse únicamente en aquellos supuestos en los cuales quien se considere dignatario de tal condición, demuestre fehacientemente encontrarse en las situaciones constitutivas de los requisitos legalmente exigidos al efecto». Tribunal Supremo, Sala de lo Civil y de lo Administrativo, Sentencia № 178 de 30 de abril de 2013, único Considerando, ponente Acosta Ricart, «se establece como requisitos para ser considerado heredero especialmente protegido que la persona de que se trate no esté apta para trabajar y que dependa económicamente del testador; circunstancias que han de concurrir de conjunto, en tanto, si faltara una de ellas no se alcanzaría esa especial condición».

24 Tribunal Supremo, Sala de lo Civil y de lo Administrativo, Sentencia № 75 de 31 de marzo de 2009, segundo Considerando, ponente Díaz Tenreiro.

25 Tribunal Provincial de Ciudad de La Habana, Sala Segunda de lo Civil y de lo Administrativo, Sentencia № 24 de 30 de abril de 2008 (Proceso Ordinario), único Considerando, ponente Méndez García, «olvida quien demanda que la condición de heredero especialmente protegido tiene que estar presente al momento de ejercitar la acción de nulidad de la institución de heredero o legatario, pues en exclusiva esta le viene atribuida cuando esté presente dicha circunstancia y es precisamente la minoría de edad del demandante y en consecuencia su dependencia económica con la testadora, lo que hacía que ostentara tal condición, lo que obviamente en la actualidad no se mantiene pues en la interposición de este proceso ya cuenta con veintiocho años de edad, según se demuestra con la correspondiente Certificación de Nacimiento que obra a fojas del expediente se este foro, significando ello que ha perdido los presupuestos jurídicos necesarios y el grado de actualidad que exige el legislador en dichas circunstancias (...) al amparo de los artículos cuatrocientos noventa y dos y cuatrocientos noventa y tres del Código Civil».

26 PÉREZ GALLARDO, L. B. (2018). Comentario al artículo 493, p. 94.

27 PÉREZ GALLARDO, L. B. y FERNÁNDEZ MARTELL, J.K (2016), p. 242, «En primer orden nuestra legítima es de naturaleza excepcional, por las razones ya apuntadas. Es tuitiva o protectora, quien percibe la legítima, a diferencia de cualquier otro legitimario lo es no solo porque es perceptor de una parte del acervo hereditario, como pars bonorum, como comunero hereditario, con derecho a una parte del activo hereditario. No se trata de un acreedor, ni tampoco de un alimentista».

28 Tribunal Supremo, Sala de lo Civil y de lo Administrativo, Sentencia № 484 de 31 de julio de 2003, segundo La letra de la norma sugeriría que los descendientes del hijo sólo pueden ser legitimados en caso de muerte prematura de su padre. Esta interpretación literal del precepto ha sido criticada, con razón, por Leonardo Pérez Gallardo, quien considera más correcto afirmar que los descendientes pueden ser también legitimarios con el hijo, siempre y cuando se den las dos condiciones exigidas por la ley. En este sentido, el ilustre maestro cubano señala que bien podría darse el caso de que el causante del daño tenga como dependientes tanto a su propio hijo como a sus nietos (los hijos de su hijo), por lo que considerar sólo al hijo como legitimario y no también al resto de descendientes (los nietos) sería improcedente. Más aún si se tiene en cuenta que al momento de identificar a los ascendientes, el legislador cubano no hace distinción alguna entre ellos, con el paradójico resultado de que en caso de fallecimiento del causante, tanto los padres del causante como los eventuales abuelos podrían unirse a los hijos y al cónyuge. Por ello, es preferible una interpretación correctora de la norma, que considera legitimados tanto al hijo como a los descendientes, aunque el hijo no sea premuerto. Considerando, ponente Acosta Ricart.

29 ALFARO GUILLÉN, Y. (2011 b), p. 264 s., " Las características fundamentales del sistema legitimario cubano son: Carácter asistencial. Naturaleza romana. Aspecto funcional perteneciente al sistema de reglamentación negativa o de freno. Determinación legal e invariable de la cuantía de las legítimas global e individual. Es de tipo 
pars bonorum dada su posibilidad de satisfacción por cualquier título. Es una legítima larga, en tanto comprende la mitad del patrimonio del causante. Opera como una limitación a la facultad dispositiva del causante mortis causa e inter vivos. Está articulado mediante normas de ius cogens. Es una legítima de concurrencia o colectiva. No tiene cabida alguna en la sucesión intestada. Equiparación de la condición legitimaria del cónyuge supérstite a la del resto de los legitimarios».

30 PÉREZ GALLARDO, L. B. (2018). Comentario al artículo 493, p. 62.

31 PÉREZ GALLARDO, L. B. (2018). Comentario al artículo 493, p. 43, «solo una interpretación correctora y racional podría salvar el precepto, de manera que sería bastante entonces que ambos vivan (hijos y nietos) a la muerte del testador, para que este se vea compelido a asignarles la cuota que le corresponde, distribuyéndose, según explicita el apartado segundo de dicho artículo, por partes iguales. Al menos de iure condendo sería una reclamación a atender».

32 Así, en cambio, Tribunal Supremo, Sala de lo Civil y de lo Administrativo, Sentencia № 872 de 29 de diciembre de 2006, segundo Considerando, ponente Arredondo Suárez, «(Al) haber quedado justificado que el causante al momento de su deceso contaba con descendencia en minoría de edad y por ende beneficiarios de la condición de herederos especialmente protegidos».

33 PÉREZ GALLARDO, L. B. (2018). Comentario al artículo 493, p. 64.

34 Tribunal Supremo, Sala de lo Civil y de lo Administrativo, Sentencia № 307 de 29 de abril de 2005, segundo Considerando, ponente Acosta Ricart.

35 Tribunal Supremo, Sala de lo Civil y de lo Administrativo, Sentencia № 814, de 21 de noviembre de 2018. Tercer Considerando. Ponente Valdés Rosabal, «contraviene la parte recurrente la situación de hecho incorporada como cierta a la sentencia, al cuestionarla sobre elementos fácticos distintos a los tenidos en cuenta para resolver la cuestión de fondo controvertida, la cual tiene como fundamento la objetividad de la especial protección que concurre a favor de las menores hijas del testador, al momento de su deceso, certeza de la que debe partir para disentir la interpelada, sin que el solo hecho de que con equívoco se haya interpretado el artículo cuatrocientos noventa y cinco del Código Civil, sea razón bastante para revocar el fallo, si traería igual consecuencia jurídica que el dictado, a saber, el restablecimiento de la lesión provocada a las legitimarias del causante por concepto de preterición». Tribunal Supremo, Sala de lo Civil y de lo Administrativo, Sentencia № 766 de 29 de octubre de 2004, segundo Considerando, ponente Arredondo Suárez, «la menor, además de cumplir el requisito de la no aptitud para trabajar, resulta inequívoco que debe considerarse dependiente económicamente del causante de la sucesión, al resultar obligación de ambos padres el sostenimiento de los hijos menores, aun cuando no tengan la patria potestad sobre ellos o no estén bajo su guarda y cuidado».

36 Tribunal Supremo, Sala de lo Civil y de lo Administrativo, Sentencia № 485, de 31 de agosto de 2017. Tercer Considerando. Ponente Acosta Ricart.

37 Tribunal Provincial de La Habana, Sala Segunda de lo Civil y de lo Administrativo, Sentencia № 88 de 25 de septiembre de 2012 (Proceso Ordinario), primer Considerando, ponente Pardo García, «la existencia de su descendiente [...] quien es menor de edad, dependía económicamente del causante y no puede insertarse a un centro laboral por encontrarse cursando estudios preuniversitarios, percibiendo el sustento de sus padres para satisfacer sus necesidades económicas más elementales, supuesto fáctico en que se hallaba, tanto al ser otorgado el testamento, como al producirse el deceso de su progenitor, motivos suficientes para estimar que reúne los requisitos para ser beneficiario de la condición de heredero especialmente protegido».

38 Tribunal Supremo, Sala de lo Civil y de lo Administrativo, Sentencia № 504 de 31 de julio de 2014, primer Considerando, ponente Díaz Tenreiro, «mantenía con éste una unión matrimonial no formalizada que cumplía los requisitos de aptitud legal, singularidad y estabilidad durante el período comprendido entre el veinticinco de enero de mil novecientos setenta y seis y el veintiséis de diciembre de dos mil siete, la que fuera reconocida judicialmente mediante sentencia firme, de ahí la condición de cónyuge sobreviviente que dependía económicamente del causante por ser ama de casa, carecer de ingresos propios y contar al momento de su fallecimiento con la edad de sesenta y dos años, por la cual no puede considerarse apta para trabajar». En el mismo sentido, Tribunal Supremo, Sala de lo Civil y de lo Administrativo, Sentencia № 80 de 29 de febrero de 2008, primer Considerando, ponente L. Hernández Pérez.

39 Tribunal Provincial de Ciudad de La Habana, Sala Segunda de lo Civil y de lo Administrativo, Sentencia № 104 de 28 de diciembre de 2007 (Proceso Ordinario), único Considerando, ponente Torres Torres. Nella sentenza si esclude che il coniuge ritornato a vivere nella casa familiare dopo lunghi anni possa considerarsi legittimario della moglie, per mancanza del requisito della dipendenza economica. « desde que se produjo el rompimiento de la relación marital de la pareja [... ] yéndose el demandante a residir fuera del domicilio conyugal por espacio 
de treinta años, período en el que la señora [... ] estableció otra relación marital no formalizada con otro hombre con el que hizo vida común por veinticinco años, y aun habiendo regresado el actor a la vivienda [... ] por petición del hijo de ambos, retorno que no significó el restablecimiento de la antigua relación de esposos; no tenían una vida en común y menos dependencia económicamente de la señora [... ] quien tenía para sustento propio una pensión por jubilación obtenida por haber laborado durante muchos años para obtener su propia economía en una vida independiente de la persona con la que solo le unió un matrimonio formal luego del rompimiento de la pareja, existiendo entre ambos además una pésima relación interpersonal donde la testadora, por razón de su género fue víctima de conducta abusiva que llegó incluso al maltrato físico por parte de quien ahora ocurrido el fallecimiento de dicha causante pretende [...] sin razón moral alguna obtener beneficio patrimonial ilegítimo en la sucesión mortis-causa».

PÉREZ GALLARDO, L. B. (2018). Comentario al artículo 493, p. 72.

41 Tribunal Provincial de Ciudad de La Habana, Sala Segunda de lo Civil y de lo Administrativo, Sentencia № 13 de 26 de marzo de 2010 (Proceso Ordinario), primer Considerando, ponente Insua Gamboa, «aprecia este foro que la cónyuge supérstite del finado [...] en vida del causante siempre dependió económicamente de éste [...] y a su vez al momento de su fallecimiento [...] contaba [...] con la edad de setenta y nueve años, edad por la cual no se puede considerar apta para trabajar y percibir gracias a su esfuerzos remuneración suficiente que le permita garantizar su vida desde el punto de vista económico si tenemos en cuenta que la edad límite exigida en nuestro ordenamiento jurídico para arribar a la jubilación y con ello dar fin a la vida laboral es la de sesenta $[\ldots]$ inferior al que contaba $[\ldots]$ al ocurrir el deceso de su relación matrimonial».

42 Tribunal Supremo, Sala de lo Civil y de lo Administrativo, Sentencia № 218, de 31 de mayo de 2011. Ponente Acosta Ricart.

43 Tribunal Supremo, Sala de lo Civil y de lo Administrativo, Sentencia № 259 de 30 de abril de 2015, segundo Considerando de la primera Sentencia, ponente Arredondo Suárez, «yerra la sala juzgadora en cuanto niega que en el caso se configura la interesada nulidad de la institución de herederos contenida en el documento notarial cuya eficacia se discute, y es que aunque sostiene que no reúne el impugnante los requerimientos de ley para estimarlo especialmente protegido, sobre la base de que el deceso de su progenitor ocurrió el trece de noviembre de dos mil trece, en momentos en que había arribado a la mayoría de edad y terminado los estudios de nivel medio superior, y aunque había optado con éxito por carrera de nivel superior, se encontraba cumpliendo la etapa de servicio militar en la brigada de lucha antivectorial, actividad socialmente útil por cuyo desempeño recibía retribución, de lo que colige que se encontraba apto y con edad para trabajar, pues podía matricular estudios universitarios en las novedosas modalidades que le permitirían estudiar y trabajar; afirmaciones con las que los sentenciadores se desentienden de la provisionalidad de la situación narrada, pues el llamado al cumplimiento del servicio militar activo, impedía a quien recurre integrarse a la reserva laboral y procurarse empleo, además de que la aludida matricula, indudable fruto de esfuerzos personales, familiares y sociales, lo era para el curso regular diurno, conforme a la planificación a cargo del Ministerio de Educación Superior, una vez vencida la etapa de sujeción a su deber patriótico-militar, lo que debe asimilarse a la no aptitud para trabajar, por tratarse de circunstancia externa y ajena a su voluntad, manteniéndose entonces la situación de dependencia económica de sus padres, parientes obligados legalmente a darle alimentos y, al no interpretarlo así, la sala de instancia resolvió con desacierto». PÉREZ GALLARDO, L. B. (2018). Comentario al artículo 493, p. 73.

PÉREZ GALLARDO, L. B. (2018). Comentario al artículo 493, p. 79.

Tribunal Supremo, Sala de lo Civil y de lo Administrativo, Sentencia № 387 de 30 de junio de 2003, único Considerando, ponente Díaz Tenreiro, «la prueba documental que acusa la recurrente como dejada de apreciar por la Sala de instancia, lo ha sido de conformidad con su específico resultado, la que por sí sola no acredita que dependiera económicamente del causante, porque tal y como acotó la sentencia interpelada si bien la pensión que recibe de la seguridad social por su condición de viuda del causante e incapacitada para laborar, quedó fehacientemente demostrado que vivió separada del mismo por muchos años, residiendo con una hija quien se ocupaba de su sostén, por esta razón resulta evidente la falta de virtualidad jurídica de la aludida prueba para determinar un pronunciamiento distinto del fallo».

47 Tribunal Supremo, Sala de lo Civil y de lo Administrativo, Sentencia № 515 de 22 de julio de 2004, segundo Considerando, ponente Arredondo Suárez, «la recurrente siempre contó con ingresos económicos propios, consistentes primero en su salario como trabajadora y luego en la pensión por edad que al obtener su jubilación comenzó a percibir, [... ] por lo que al no existir la aludida dependencia forzosamente ha de estimarse que no le asiste el derecho a tal especial protección y, por ende, al no encontrarse limitada la libertad de testar no puede 
ser cuestionada la eficacia del legado contenido en el impugnado instrumento público». En sentido idéntico, Tribunal Supremo, Sala de lo Civil y de lo Administrativo, Sentencia № 475 de 4 de noviembre de 2011, único Considerando de la primera Sentencia, ponente Arredondo Suárez, «se desentiende de la connotación que alcanza el hecho que sienta, referido a que la designada como heredera especialmente protegida es beneficiaria del Sistema de Seguridad Social, por disfrutar de pensión ordinaria por edad, circunstancia que denota que no dependía económicamente del causante y que carece por ende, de presupuesto básico para ostentar tal condición sucesoria».

48 Tribunal Supremo, Sala de lo Civil y de lo Administrativo, Sentencia № 317 de 30 de mayo de 2007, primer Considerando, ponente Carrasco Casi, «al quedar justificado en el pleito que ésta (la recurrente) disfrutaba de una prestación de la seguridad social a largo plazo, obvio resulta que no se encontraba en una situación que no podía valerse por sí misma, sino que al acogerse a la pensión que disfrutaba dicho causante, ejercitó el derecho de opción que concede el artículo dieciséis de la Ley veinticuatro de Seguridad Social de veintiocho de agosto de mil novecientos setenta y siete».

49 Para un comentario en profundidad sobre esta sentencia, v. PÉREZ GALLARDO, L. B. (2018). Comentario al artículo 493, p. $76 \mathrm{~s}$.

50 Tribunal Supremo, Sala de lo Civil y de lo Administrativo, Sentencia № 482 de 21 de octubre de 2013, segundo Considerando, ponente Díaz Tenreiro, «si bien quedó justificado que al momento de su fallecimiento, el testador se encontraba legalmente casado con la recurrente, y por tal razón se sobreentiende que el fallecido, tenía participación en la unidad económica del núcleo familiar que conformaba, al recibir la actora pensión de seguridad social es evidente que no dependía económicamente del causante y ello descarta su condición de heredera especialmente protegida que regula el apartado uno del artículo cuatrocientos noventa y tres del Código Civil». Contra, Tribunal Supremo, Sala de lo Civil y de lo Administrativo, Sentencia № 178 de 30 de abril de 2013, único Considerando, ponente Acosta Ricart, «que la actora estaba casada legalmente con el testador, que no estaba vinculada al trabajo, pero además que al momento de fallecer su esposo concurría en la misma inaptitud para trabajar esencialmente por razón de la edad, pues contaba entonces con sesenta y seis años; todo ello, unido a la dependencia económica del testador, lo que incluso motivó que le fuera concedida pensión por la Seguridad Social como viuda del mismo; de donde, al concurrir en su persona las condiciones que se exigen por el precepto legal antes mencionado, no cabe dudar que la misma debe ser considerada heredera especialmente protegida de su fallecido esposo».

51 Tribunal Supremo, Sala de lo Civil y de lo Administrativo, Sentencia № 430, de 29 de agosto de 2017. Único Considerando de la primera Sentencia. Ponente Arredondo Suárez.

52 Tribunal Supremo, Sala de lo Civil y de lo Administrativo, Sentencia № 784, de 31 de octubre de 2017. Primer, Segundo y Cuarto Considerando, respectivamente. Ponente Arredondo Suárez, «resulta incuestionable que los esposos dependían uno del otro, cumpliendo de esa manera con los deberes del matrimonio tal y como lo prevé la norma especial en la materia, como resulta el brindarse ayuda mutuamente, cuidar de la familia, y en la medida de sus capacidades y posibilidades participar en el gobierno del hogar, cooperando al mejor desenvolvimiento de este, satisfaciendo las necesidades de la familia según sus facultades y necesidades económicas, incluida la obligación de darse alimentos, de lo que se evidencia que estimar que la cónyuge sobreviviente no gozaba de la condición de heredera especialmente protegida por el solo hecho de que su fallecido esposo no contara con retribución periódica, contraría los principios que informan el matrimonio en nuestra sociedad; a lo que se adiciona la no aptitud para trabajar de la demandante en razón de la edad, y que aunque percibía una pensión ascendente a doscientos pesos cubanos, dicha prestación resultaba a todas luces insuficiente para satisfacer los gastos corrientes de personas de la tercera edad, requeridas de alimentación balanceada y que por lo general deben adquirir medicamentos regulados que conllevan la erogación de gran parte de lo que reciben por seguridad social, de manera que para su subsistencia le resultaba indispensable el aporte económico de su cónyuge, quien tenía ahorros depositados en entidad bancaria, con el que conformó una unidad económica de la que dependía».

53 Tribunal Supremo, Sala de lo Civil y de lo Administrativo, Sentencia № 532 de 29 de diciembre de 2011, primer Considerando, ponente Bolaños Gassó, «no concurre a favor de [...], hijo del testador [...] la cualidad que propugna la especial protección que el artículo cuatrocientos noventa y tres del Código Civil dispensa para aquellos que no estén aptos para trabajar y dependan económicamente del causante, y no acreditado el último presupuesto al encontrarse desde mil novecientos ochenta y tres sometido a un régimen de internado con asistencia gratuita, cubriendo la institución estatal las necesidades elementales de sustento, habitación y vestido, dada la enfermedad que padece consistente en un retraso mental severo, que condujo a la declaración 
judicial de su incapacidad y a proveerlo de tutor, sin que se obtuviera acreditación siquiera de la exigida responsabilidad económica del causante a favor de su hijo, situación fáctica que no quedó desvirtuada del resultado de la prueba señalada por quien recurre».

PÉREZ GALLARDO, L. B. (2018). Comentario al artículo 492, p. 27 s., «y aunque el legislador no se refiere también a la condición, tampoco lo considero plausible, porque de satisfacerse la legítima a título de herencia, rige la prohibición de supeditar la institución de heredero a condición, contenida en el artículo 481 del Código Civil; de hacerlo a título de legado, rige igual prohibición prevista en el artículo 498 del propio texto legal; incluso, de satisfacerse a través de una donación, de igual manera esta no pudo haberse supeditado a dicho elemento accidental, conforme con la prescripciones del artículo 376 del mismo Código».

55 ALFARO GUILLÉN, Y. (2015). p. 120, define estas cláusulas como aquellas que «consisten en previsiones sobre la posible dispensa de protección legitimaria que al momento de su estipulación carecen de certidumbre». PÉREZ GALLARDO, L. B. (2018). Comentario al artículo 493, p. 88, «no se hace necesario que al m omento del otorgamiento del testamento se cumplan con los requerimientos o presupuestos para arroparse con la especial protección. Ni siquiera es necesario que el sujeto exista. Lo que importa es que exista en el momento del fallecimiento o que al menos se trate del nasciturus [... ] Por ello, y a los fines de evitar situaciones de preterición, es conveniente el empleo, al menos en sede notarial, de las cláusulas de protección genérica de la legítima».

56 Tribunal Supremo, Sala de lo Civil y de lo Administrativo, Sentencia № 393, de 9 de septiembre de 2020. Primer Considerando. Ponente Acosta Ricart, «contiene el Testamento [... ] autorizado por la fedataria [...] la Cláusula Primera denominada de protección genérica de la legítima, al dejar constancia el autor del instrumento público que, reserva, para quienes acrediten tener la condición al momento de su fallecimiento lo que por Ley les pudiera corresponder; de lo que es obligado colegir que aunque no reconoció a la recurrente como tal de forma expresa, el hecho de exponer su ánimo de protección hacia aquellos herederos que acrediten dicha circunstancia a su muerte, ha de entenderse según el sentido lato de la cláusula que al unísono salvaguarda a quienes igualmente estén dotado de la especial cualidad con anterioridad a su defunción; por consiguiente, debe deducirse incluida entre los legitimarios para el ejercicio de la acción encaminada a la ejecución del testamento de cara a la adjudicación de la mitad de la herencia dejada por su causante, quedando para la instituida la porción de libre disposición del testador».

57 PÉREZ GALLARDO, L. B. (2018). Comentario al artículo 492, p. 27.

58 PÉREZ GALLARDO, L. B. (2018). Comentario al artículo 492, p. 28 s., «si la vivienda es destinada para satisfacer la cuota de legítima que le corresponde a los especialmente protegidos que tuviera el testador, ahora devenido causante, la legítima estaría gravada con un derecho a favor de un tercero por disposición de la ley. El titular del inmueble, no obstante, pudiera evitarlo, tan solo si ejercita en vida la facultad reconocida en el artículo 64 de la mencionada Ley General de la Vivienda, de manera que a su fallecimiento deje la vivienda libre de ocupantes que pudieran quedar protegidos bajo el imperio del artículo 77.4 de dicha Ley. En sede de intangibilidad cualitativa de la legítima, el legislador patrio peca por ser extremadamente escueto».

59 Es conocida la tesis de FERRI, L. (1965), p. 103 ss., según el cual la diferencia entre la acción de reducción y la de prohibición de gravámenes y condiciones se aprecia atendiendo al elemento causal de la lesión. Cuando la lesión constituye la causa del acto de última voluntad, es decir, existe una intención por parte del testador de perjudicar los derechos de los legitimarios, la disposición es sancionada por nulidad; en los casos en que la lesión no constituye la causa del acto de última voluntad, el legitimado debe interponer una demanda de reducción.

60 ALFARO GUILLÉN, Y. (2021), p. 172, «La frecuente asimilación del derecho al complemento a las acciones que permiten su ejercicio y satisfacción, crea un imponente obstáculo de origen en la evolución del instituto, generado por la terminología de acción de complemento o de suplemento de legítima. Completar la porción del sucesor forzoso que ve menguada su cuantía, es la finalidad con la que se le confieren al vulnerado, un conjunto de posibilidades impugnatorias mediante la reducción, la rescisión, la inclusión y la colación. Estas alternativas, logran el doble cometido de dejar sin efecto el acto o negocio que quebranta la intangibilidad cuantitativa de la legítima y de reintegrar el quantum debido al legitimario. Así pueden atribuírseles una dualidad de efectos: los que generan la ineficacia de los actos que lesionan al legitimario y los que restablecen la integridad de su cuota».

61 ALFARO GUILLÉN, Y. (2018), Comentario al artículo 494, p. 111.

62 Tribunal Supremo, Sala de lo Civil y de lo Administrativo, Sentencia № 120 de 28 de febrero de 2005, único Considerando, ponente Acosta Ricart, .lo cierto es que por sentencia firme se dispuso la nulidad del acto jurídico consistente en Testamento Notarial contenido en la Escritura número [...] otorgada [...] por el hecho de haberse infringido lo concerniente a la designación del heredero especialmente protegido, en este caso un hijo menor de edad, por lo que intrascendente resulta que con posterioridad a la firmeza de dicha sentencia dicho menor 
hubiere abandonado el país definitivamente, pues para entonces ya había surtido todos los efectos legales en cuanto a la nulidad del mencionado instrumento, abriéndose así la sucesión intestada como en efecto fue verificado, alcanzando por tanto tal nulidad a los actos realizados en virtud del instrumento declarado nulo, en este caso, el acto jurídico de Aceptación y Adjudicación de Herencia contenido en la correspondiente escritura, respecto al cual se interesó su nulidad en el presente proceso». Tribunal Supremo, Sala de lo Civil y de lo Administrativo, Sentencia № 422 de 18 de noviembre de 2011, único Considerando de la segunda Sentencia, ponente Bolaños Gassó, .al ser desconocida en el testamento que otorgó a favor de persona distinta, ello deviene clara situación de preterición que invalida dicha institución y que obliga acudir a la persona interesada a los trámites de la herencia intestada».

63 ALFARO GUILLÉN, Y. (2018), Comentario al artículo 494, p. 109 s.

64 Tribunal Supremo, Sala de lo Civil y de lo Administrativo, Sentencia № 58 de 23 de marzo del 2009, primer Considerando, ponente González García, «la institución de la inoficiosidad de donaciones declaradas post mortem tiene su sustento en la protección de los derechos hereditarios de quienes pudieren resultar eventuales sucesores del donante, impidiendo a éste efectuar en vida actos de liberalidad de semejante naturaleza por los que, con defraudación de aquellos, dispusiera de todo su patrimonio o de parte sustancial de él, afectando la porción que la ley reserva a los herederos especialmente protegidos y creando de tal suerte una situación de franca indefensión de dichos legitimarios frente a donatarios adquirentes de buena fe; razón por la que el artículo setenta y seis, apartado d, del Código Civil, establece que son rescindibles los actos válidamente realizados por los causantes, en el caso de donaciones inoficiosas, mientras que el artículo trescientos setenta y ocho, apartado a, del propio cuerpo legal, por su parte prescribe que es rescindible, por inoficiosa, la donación que excede lo que puede darse o recibirse por testamento, lo que tiene claro basamento en el principio de que nadie puede ofrecer más de lo que tiene ni disponer de aquello de lo que carece y en consecuencia, habrá de estarse al momento del fallecimiento del donante, instante en que conforme al artículo quinientos veintidós del Código Civil adquieren la herencia sus sucesores, para determinar si resulta inoficiosa una donación que hubiere en vida efectuado y que en consecuencia no podrá ser impugnada por tal en tanto no se produjere el fallecimiento del donante, puesto que es en ese instante que cabe valorar la ascendencia del caudal hereditario a los efectos de determinar si ese acto de liberalidad ha comprometido o no la parte reservada por el legislador para quienes eventualmente resultaran sus legitimarios especialmente protegidos, de haberse deferido la herencia por testamento, que importa la mitad de la misma, de la que el donante en tal supuesto no podía disponer en virtud de que el artículo cuatrocientos noventa y dos, apartado primero, del Código Civil, limita en tales casos al testador la disponibilidad de la herencia a la mitad de ella, reservando la restante a los mencionados legitimarios, habida cuenta que obviamente entre el momento del otorgamiento del contrato de donación que se repute de inoficioso y el deceso del donante es susceptible de variación el monto del haber hereditario y ello podría determinar que una donación que resultare eventualmente inoficiosa al momento de su otorgamiento no lo fuere al instante del fallecimiento del donante en que su herencia es transferida a sus herederos si en el ínterin hubiere experimentado acrecimiento el patrimonio de aquél [...]».

65 Véase el artículo 555 Código civil italiano.

66 DíEZ-PICAZO Y GULLÓN (2017), pp. 178-181.

67 Tribunal Supremo, Sala de lo Civil y de lo Administrativo, Sentencia № 239 de 31 de mayo de 2013, tercer Considerando, ponente Acosta Ricart, «ciertamente resulta desacertada la forma en que a través de su representante legal; o sea su tutora, se encausó la impugnación; ya que, a su elección sólo se interesó la nulidad total de uno de los legados, cuando en puridad no establecida por el testador para caso de impugnación, orden de prelación de los mismos; la acción debe estar encaminada a impugnar ambos por igual, en la medida que sea suficiente hasta llegar a la porción de la herencia que por Ley le corresponde».

68 ALFARO GUILLÉN, Y. (2021), p. 187, «predomina afortunadamente el criterio de la prevalencia de la atribución sobre la mención, aunque valga precisar, lo valedero de estimar que en cualquiera de los dos supuestos por separado siempre que se verifiquen como se ha descrito en las líneas anteriores, debe entenderse excluida la preterición. De este modo el cumplimiento de los deberes formal y material de legítimas no deben ser integrados en el concepto de preterición en relación preponderante sino de ubicación en un mismo plano a los efectos de su exclusión».

69 Tribunal Supremo, Sala de lo Civil y de lo Administrativo, Sentencia № 317 de 12 de mayo de 2005, primer Considerando, ponente González García, .en el caso concurre la modalidad de omisión de legitimario que en la doctrina jurídica se conoce como real o material, en la que el testador, pese a que hace mención en el testamento de la persona en quien concurre la especial protección, si bien no le atribuye expresamente 
esa condición; luego la excluye al asignar el destino que tendrán los bienes y derechos que conforman su herencia, no reservándole la mitad de la misma que nuestra legislación sustantiva civil le destina forzosamente como legítima; pues acto seguido a esa simple mención nombra como único y universal heredero a un tercero, lo que ocasiona indefectiblemente la nulidad de la institución de heredero como terminantemente establece el artículo cuatrocientos noventa y cinco, inciso primero, del Código Civil; a diferencia de la llamada omisión formal, donde a contrario sensu el testador, a pesar de no reconocer expresamente la condición de su legitimario, sin embargo le reserva la porción de legítima que le corresponde». En idéntico sentido, Tribunal Supremo, Sala de lo Civil y de lo Administrativo, Sentencia № 53 de 12 de febrero de 2016, primer Considerando, ponente Arredondo Suárez.

70 Tribunal Supremo, Sala de lo Civil y de lo Administrativo, Sentencia № 408 de 30 de junio de 2014, primer Considerando, ponente Acosta Ricart, «la preterición es un término de la sucesión testada, en la sucesión abintestato, lo que ocurre es la omisión de alguno de los presuntos herederos del causante que debieron ser declarados como tal».

71 Tribunal Supremo, Sala de lo Civil y de lo Administrativo, Sentencia № 427 de 30 de diciembre de 2010, primer Considerando, ponente Acosta Ricart, «el término preterición, en su concepción teórica básica o más elemental, equivale a la omisión de un heredero en el testamento, o sea que la exclusión ya sea por olvido, o intencional es imputable al testador, por ello y aun cuando se reconoce que en no pocas ocasiones el citado término jurídico se utiliza indistintamente para cualquiera de las formas en se hubiere determinado la sucesión, o sea tanto para la testamentaria como para la intestada, incluso ha sido mal utilizada en la denominación de algunos procesos que se han seguido ante nuestros tribunales, su mal uso, por más o menos generalizado que sea no convalida el defecto, razón que ha obligado a esta Sala dejar establecida su posición en cuanto a que, sólo puede estimarse preterición cuando se trate de herencia testada; de donde tanto por el Tribunal actuante como por la propia recurrente se ha usado indebidamente el referido término». En igual sentido, Tribunal Supremo, Sala de lo Civil y de lo Administrativo, Sentencia № 35 de 31 de enero de 2008, único Considerando, ponente Acosta Ricart.

72 ALFARO GUILLÉN, Y. (2018), Comentario al artículo 495, p. 138, «Así, puede definirse como la institución jurídica que califica la situación en la que se encuentra el legitimario cuando se ha omitido en testamento su condición sin que tampoco haya existido atribución alguna mortis causa o por actos inter vivos realizados por el testador a su favor».

73 Tribunal Provincial de Ciudad de La Habana, Sala Segunda de lo Civil y de lo Administrativo, Sentencia № 13 de 26 de marzo de 2010 (Proceso Ordinario), tercer Considerando, ponente Insua Gamboa, «y la preterición de éstos sin duda alguna conlleva, a tenor de lo previsto en el artículo cuatrocientos noventa y cinco, apartado primero del cuerpo legal en comento, a la nulidad de la institución de herederos contenida en el acto jurídico unilateral con independencia de que este olvido de mención y atribución patrimonial hubiese sido de forma voluntaria o no».

74 Tribunal Provincial de Ciudad de La Habana, Sala Segunda de lo Civil y de lo Administrativo, Sentencia № 27 de 30 de marzo de 2007 (Proceso Ordinario), primer Considerando, ponente Alfaro Guillén, «la preterición de algún heredero especialmente protegido, en que incurra el testador, acarrea el efecto de la nulidad de la cláusula de institución de herederos y no del negocio jurídico testamentario». En este sentido, Tribunal Supremo, Sala de lo Civil y de lo Administrativo, Sentencia № 395 de 27 de diciembre de 2010, único Considerando, ponente Acosta Ricart; Tribunal Supremo, Sala de lo Civil y de lo Administrativo, Sentencia № 367 de 13 de agosto de 2013, único Considerando, ponente Acosta Ricart.

75 ALFARO GUILLÉN, Y. (2021), p. 188 s., «la preterición genera efectos que se ubican en planos diferentes: efectos preliminares y efectos definitivos. En un plano preliminar, tienen lugar efectos o acciones impugnatorias por preterición: nulidad, reducción/rescisión, inclusión/reforma, cuyo objeto es inhibir los efectos básicos de las lesiones legitimarias cometidas a través de los actos lucrativos inter vivos, o las disposiciones testamentarias inoficiosas del testador [...] tras el ejercicio exitoso de las acciones por preterición, se despliega un segundo conjunto de efectos mucho menos explorados por los estudiosos del tema. Los efectos definitivos son los que permiten al legitimario adquirir lo que por legítima le corresponde tras el éxito de los efectos preliminares, por los cauces que la ley prevé. Esos otros cauces son los efectos definitivos de la preterición, que se concretan en el título sucesorio por el que finalmente acude a la sucesión el preterido y en el título adquisitivo de su porción». V. también, ALFARO GUILLÉN, Y. (2018), Comentario al artículo 495, p. 140 ss.; ALFARO GUILLÉN, Y. (2011 b), p. 256. ALFARO GUILLÉN, Y. (2018), Comentario al artículo 495, p. 150. 
77 Cabe señalar que conforme al artículo 115 del Reglamento de la Ley de las notarías estatales, los notarios pueden autorizar Actas de Declaratorias de Herederos ab intestato. La declaración de heredero intestado es competencia de las secciones civiles de los tribunales municipales populares en casos excepcionales. 